\title{
Imaging of Portal Gastroduodenopathy
}

\author{
Rajesh V. Helavar ${ }^{1} \quad$ Vidyasagar Ramappa ${ }^{2}$ Praveen P. Wali ${ }^{3}$ \\ ${ }^{1}$ Department of Diagnostic and Interventional Radiology, Columbia \\ Asia Radiology Group, Bengaluru, Karnataka, India \\ ${ }^{2}$ Department of Gastroenterology and Hepatology, Columbia Asia \\ Referral Hospital, Bengaluru, Karnataka, India \\ ${ }^{3}$ Department of Diagnostic Radiology, Columbia Asia Radiology \\ Group, Bengaluru, Karnataka, India
}

\begin{abstract}
Address for correspondence Rajesh V. Helavar, MD, PDCC, Department of Diagnostic and Interventional Radiology, Columbia Asia Radiology Group, Bengaluru 560055, Karnataka, India (e-mail: rajeshvhelavar@gmail.com).
\end{abstract}

J Gastrointestinal Abdominal Radiol ISGAR 2021;4:177-193.

\begin{abstract}
Keywords

- BRTO

- gastric varices

- portal gastropathy

- portal hypertension

- portosystemic collaterals

- TIPS

Portal hypertension is characterized by elevated pressure in portal venous system due to portal resistance due to various causes. The etiologies are either pre-hepatic, hepatic, or post-hepatic. Elevated portal pressure results in varices at various sites some of which are difficult to identify on endoscopy alone. Other manifestations of elevated portal pressure include portal gastropathy, enteropathy, colopathy, gastric antral vascular ectasia, and ascites. Imaging plays an essential role in diagnosis and imaging of various manifestations of portal hypertension by determining the locations of varices and plan the management for same. Endoscopy helps in visualizing mucosal varices but newer imaging modalities give a panoramic extent of the disease in the entire gastrointestinal tract with great specificity and sensitivity. Initially, Barium study was used to determine esophageal or gastric varices, computed tomography provides detailed anatomic information which can be used to plan management. Due to advancement in imaging and interventional techniques, treatment for varices has seen advent of multiple minimally invasive interventional radiological techniques. A brief outlook on anatomical aspect of varices and various recent advances in management of the same has been provided. Overall knowledge of the various imaging manifestations of portal hypertension can be helpful to evaluate prognosis and plan proper management.
\end{abstract}

\section{Introduction}

Portal hypertension is a syndrome of increased pressure $(>5 \mathrm{~mm} \mathrm{Hg}$ ) in portal venous system resulting from changes in portal resistance plus changes in portal inflow. It is a progressive complication due to chronic liver disease and is responsible for the pathogenesis of most frequent and fatal complications of cirrhosis such as esophagogastric varices, ectopic varices, ascites, and hepatic encephalopathy. Bleeding from the esophagogastric varices or ectopic varices is the most critical complication of portal hypertension.

\section{Anatomy}

\section{Venous Drainage of Stomach}

The left gastric vein, also known as the coronary vein, courses along the lesser curvature of the stomach, drains both the

published online

August 9, 2021
DOI https://doi.org/

10.1055/s-0041-1728235

ISSN 2581-9933 surfaces of stomach, and drains into the portal vein. At the esophagogastricjunctionitalsodrains loweresophagealveins. ${ }^{1}$ The right gastric vein also drains the lesser curvature of the stomach into the portal vein. The left gastric vein is one of the important channels for portosystemic collateral through the esophageal veins to the azygous venous system. Multiple short gastric veins coursing in the gastrosplenic ligament drain the fundus and greater curvature of stomach to the splenic vein (-Fig. 1).

The left and right gastroepiploic veins course along the greater curvature and drain into the splenic and the superior mesenteric veins, respectively. ${ }^{2}$ The posterior gastric vein drains the esophagogastric region, courses in retro pancreatic location, and drains into the splenic vein. ${ }^{3}$ Portosystemic communications exist normally and show hepatofugal flow. Onset of portal hypertension leads to increased flow in these collaterals. $^{2}$ The second and third parts of duodenum are

(c) 2021. Indian Society of Gastrointestinal and Abdominal Radiology. This is an open access article published by Thieme under the terms of the Creative Commons Attribution-NonDerivative-NonCommercial-License, permitting copying and reproduction so long as the original work is given appropriate credit. Contents may not be used for commercial purposes, or adapted, remixed, transformed or built upon. (https://creativecommons.org/licenses/by-nc-nd/4.0/).

Thieme Medical and Scientific Publishers Pvt. Ltd. A-12, 2nd Floor,

Sector 2, Noida-201301 UP, India 


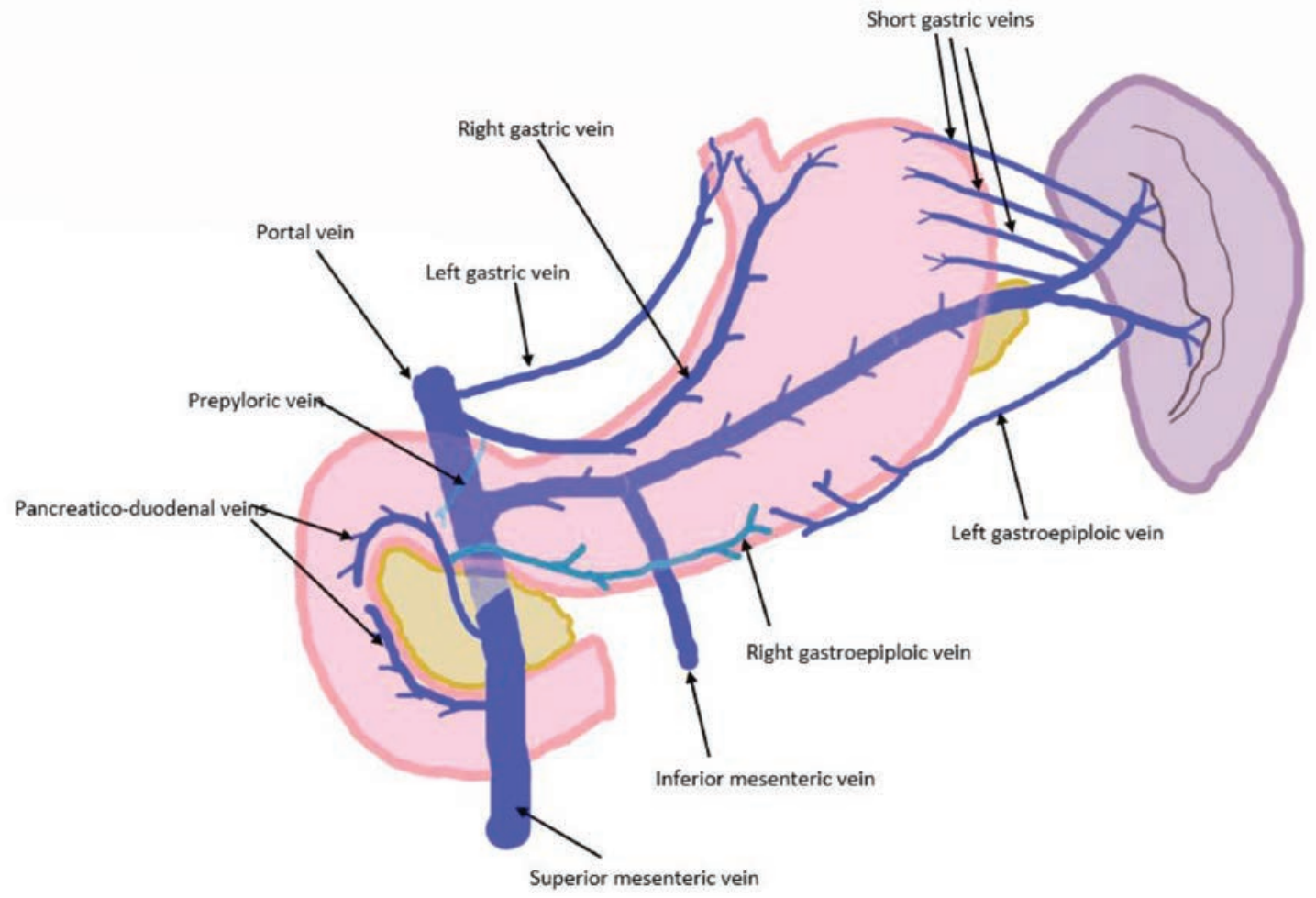

Fig. 1 Venous drainage of the stomach and duodenum. (Image Credit: Dr Rajaraman V, Columbia Asia Radiology Group).

drained by anterior and posterior venous arcades formed by their superior and inferior veins. The posterosuperior pancreaticoduodenal vein drains into the portal vein. The anteriosuperior pancreaticoduodenal vein and both the inferior pancreaticoduodenal veins drain into superior mesenteric vein, gastrocolic trunk, or into the first jejunal trunk.

The nonesophagogastric portosystemic collaterals are superior rectal vein with the middle and inferior rectal veins, paraumbilical vein with subcutaneous veins in the anterior abdominal wall, veins of the bare area of the liver with diaphragmatic veins, and right internal thoracic vein. ${ }^{4,5}$ The direction of collateral flow depends on the cause and site of obstruction. In portal hypertension due to cirrhosis the flow is hepatofugal, whereas in case of extrahepatic portal venous obstruction (EHPVO) the flow is hepatopetal. This is not exclusive and combinations can occur ${ }^{5,6}$

\section{Causes of Portal Hypertension}

Portal hypertension can arise from any condition interfering with blood flow at any level within the portal system. Portal hypertension is primarily a complication of cirrhosis, but other conditions may also cause portal hypertension.

Portal hypertension may be classified according to the anatomical location of etiology:

1. Prehepatic (extra hepatic): Characterized by normal values for free hepatic venous pressure (FHVP), wedged hepatic venous pressure (WHVP), right atrial pressure (RAP), and hepatic venous pressure gradient (HVPG).

\section{Hepatic (intrahepatic).}

a. Presinusoidal: Characterized by normal FHVP and RAP and normal or near normal WHVP and HVPG. b. Sinusoidal: Characterized by increased HVPG (primary cause is hepatic cirrhosis).

c. Postsinusoidal: Characterized by high FHVP and WHVP, normal RAP, and normal to high HVPG.

3. Posthepatic: Characterized by normal or near-normal HVPG, normal or high FHVP and RAP, and high WHVP.

Cirrhotic portal hypertension may now be classified according to degree of hypertension and state of underlying cirrhotic disease (compensated vs. decompensated).

\section{Compensated cirrhosis.}

a. Mild portal hypertension: $\mathrm{HVPG}>5 \mathrm{~mm} \mathrm{Hg}$ and $<10 \mathrm{~mm} \mathrm{Hg}$.

b. Clinically significant portal hypertension(CSPH): $H V P G \geq 10 \mathrm{~mm} \mathrm{Hg}$.

- CSPH without varices.

- CSPH with varices.

\section{Decompensated cirrhosis.}

Noncirrhotic portal hypertension is usually classified according to the underlying etiology. The major noncirrhotic conditions include the following:

- Extrahepatic portal vein obstruction (EHPVO).

- Splenic vein thrombosis or left-sided portal hypertension (LSPH).

- Idiopathic noncirrhotic portal hypertension.

- Liver periportal fibrosis from schistosomiasis.

- Nodular regenerative hyperplasia.

- Veno-occlusive disease.

- Budd-Chiari syndrome. 


\section{Endoscopic Diagnosis of Portal Hypertension}

As chronic liver disease advances and portal venous pressure increases, many portal-systemic collateral routes develop. Esophagogastric varices are part of the clinical manifestations of these portal-systemic collateral routes and can be observed directly beneath the esophageal and/or gastric mucosa on endoscopic examination.

\section{Manifestations of Portal Hypertension in the Gastrointestinal (GI) Tract}

Following are the manifestations of portal hypertension in the GI tract:

1. Varices.

- Esophageal varices.

- Gastric varices.

- Ectopic varices.

- Rectal varices.

2. Portal hypertensive gastropathy, enteropathy, and colopathy.

3. Gastric antral vascular ectasia.

\section{Varices}

Varices are present in about $50 \%$ of patients with cirrhosis and form at the rate of $5-15 \%$ per year. ${ }^{7}$ The risk of varices is low in patients who have cirrhosis but normal platelet count or a liver stiffness measured by transient elastography of less than $20 \mathrm{kPa} .{ }^{8}$

Esophageal varices: These are long columns of dilated veins occurring in the lower third of the esophagus above the gastroesophageal junction. Usually four esophageal varices are formed in the submucosal layer fed by the palisading veins that represent the portosystemic anastomosis. Esophageal varices are classified based on the size as depicted in the - Table 1 (-Fig. 2).
Gastric varices: These are supplied by the short gastric veins and drain into the deep intrinsic veins of the esophagus and are classified according to the site by Sarin's classification ( - Table 2 ; - Figs. 3 and $\mathbf{4}$ ). ${ }^{9}$

Ectopic varices: Duodenal varices are often diagnosed at the time of hemorrhage. They appear as protruded lesions with erosions or using/oozing of blood at the time of bleed. When not bleeding they appear as elevated or tortuous submucosal lesions that sometimes may be mistaken for submucosal lesions ( - Fig. 5). Majority of the duodenal varices occur in the bulb. ${ }^{10}$

Colorectalvarices: The rectum is the region where portosystemic shunts are prone to develop after the esophagogastric area. The locations of the colorectal varices are predominantly the rectum $(66.7 \%)$, the Sigmoid colon (22.2\%), and the cecum (16.7\%). ${ }^{10}$

\section{Imaging of Esophagogastric Varices}

Esophageal varices are best evaluated with endoscopy but are commonly seen on barium and computed tomography (CT) done for evaluation of portal hypertension, cirrhosis, or screening for hepatocellular carcinoma.

On double-contrast barium studies esophageal varices are seen as serpiginous thickening of the folds. Mild fold

Table 1 Classification of esophageal varices

\begin{tabular}{|l|l|l|}
\hline & $\begin{array}{l}\text { Two-size } \\
\text { classification }\end{array}$ & Three-size classification \\
\hline Small & $<5 \mathrm{~mm}$ & $\begin{array}{l}\text { Minimally elevated straight veins } \\
\text { above the mucosal surface (grade I). }\end{array}$ \\
\hline Medium & $\begin{array}{l}\text { Tortuous veins occupying less than } \\
\text { one-third of the lumen (grade II). }\end{array}$ \\
\hline Large & $>5 \mathrm{~mm}$ & $\begin{array}{l}\text { Tortuous being occupying more } \\
\text { than one-third of the lumen } \\
\text { (grade III). }\end{array}$ \\
\hline
\end{tabular}

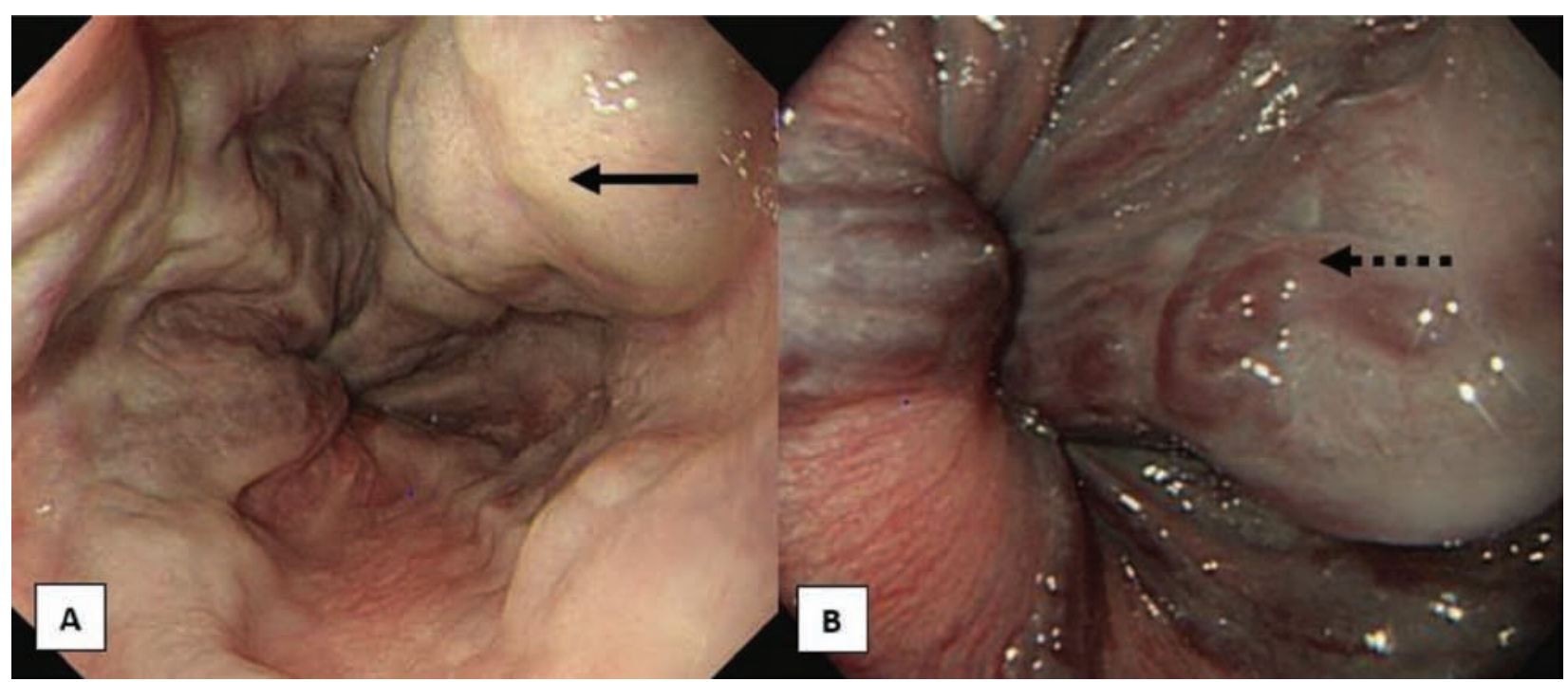

Fig. 2 Esophageal varices. (A) Well-covered white color (arrow) (low risk of bleeding). (B) Thinned-out bluish red color (dotted arrow) with red wale signs (high risk of bleeding). 
Table 2

\begin{tabular}{|l|l|}
\hline $\begin{array}{l}\text { Sarin's type of } \\
\text { gastric varix }\end{array}$ & Description/location \\
\hline GOV1 & $\begin{array}{l}\text { Continue from the esophageal varices and } \\
\text { extend on the lesser curve (75\% of all gastric } \\
\text { varices). }\end{array}$ \\
\hline GOV2 & $\begin{array}{l}\text { Extend beyond the GE junction into the funds } \\
\text { the stomach and are continuous with the eso- } \\
\text { phageal varices (21\% of all gastric varices). }\end{array}$ \\
\hline IGV1 & $\begin{array}{l}\text { Occur in the absence of esophageal varices } \\
\text { and occur in the fundus and are tortuous and } \\
\text { complex. }\end{array}$ \\
\hline IGV2 & $\begin{array}{l}\text { Occur in the absence of esophageal varices } \\
\text { and occur in the body, antrum, or pylorus. }\end{array}$ \\
\hline
\end{tabular}
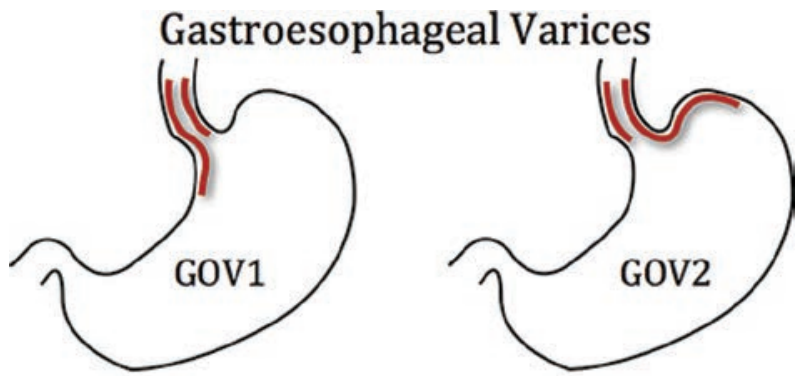

\section{Isolated Gastric Varices}
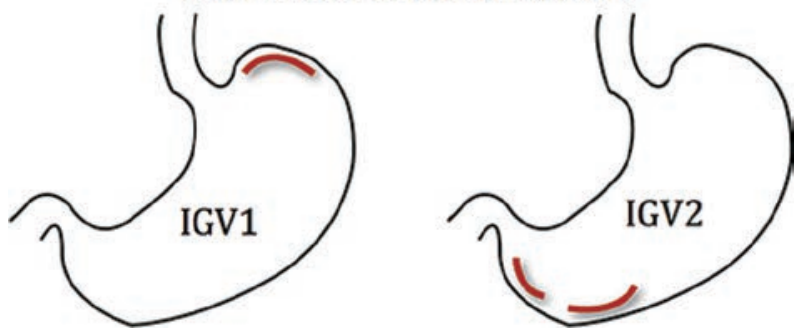

Fig. 3 Gastric varices-Sarin's classification. ${ }^{9}$ GOV1: Continue from the esophageal varices and extend on the lesser curve. GOV2: Extend beyond the gastroesophageal junction into the kudus of the stomach and continuous with the esophageal varices. IGV1: Occur in the absence of esophageal varices in the funds and are tortuous and complex. IGV2: Occur in the absence of esophageal variances and found in the body, antrum, or pylorus.

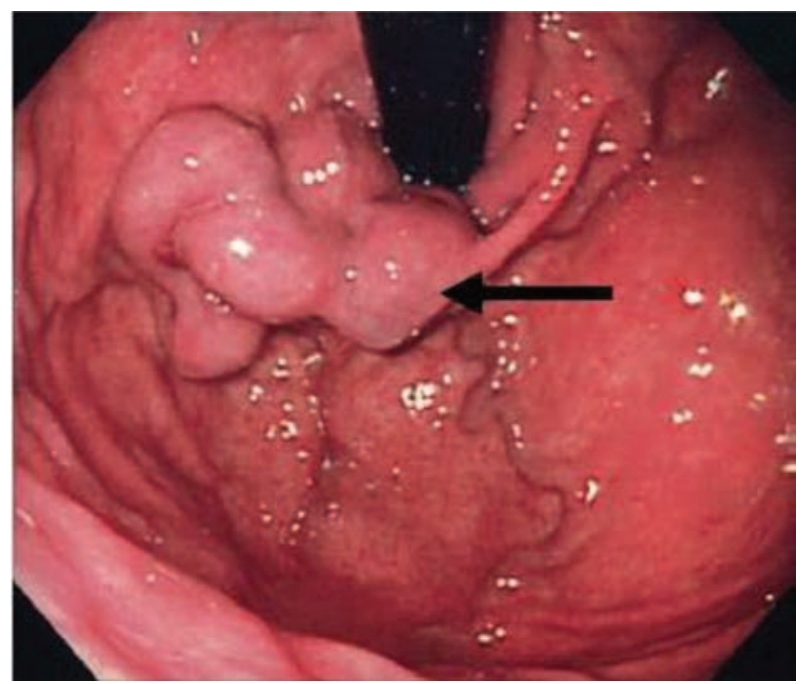

Fig. 4 Isolated gastric varix (IGV1): Cluster of tortuous dilated submucosal vessels (arrow) in the fundus of the stomach.

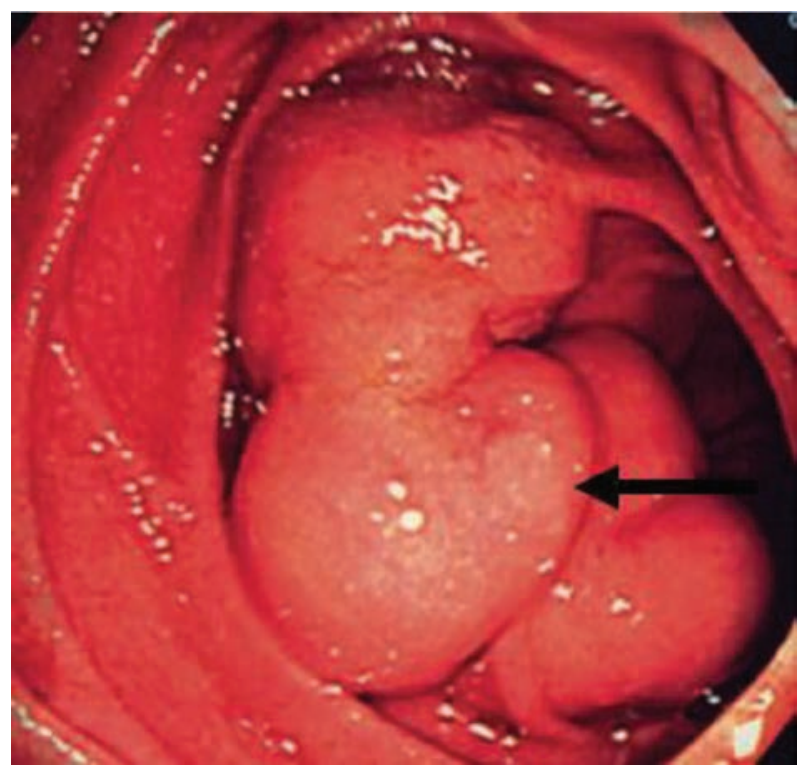

Fig. 5 Endoscopic findings of ectopic varices. Duodenal varices (arrow) are recognized as elevated tortuous submucosal lesions.

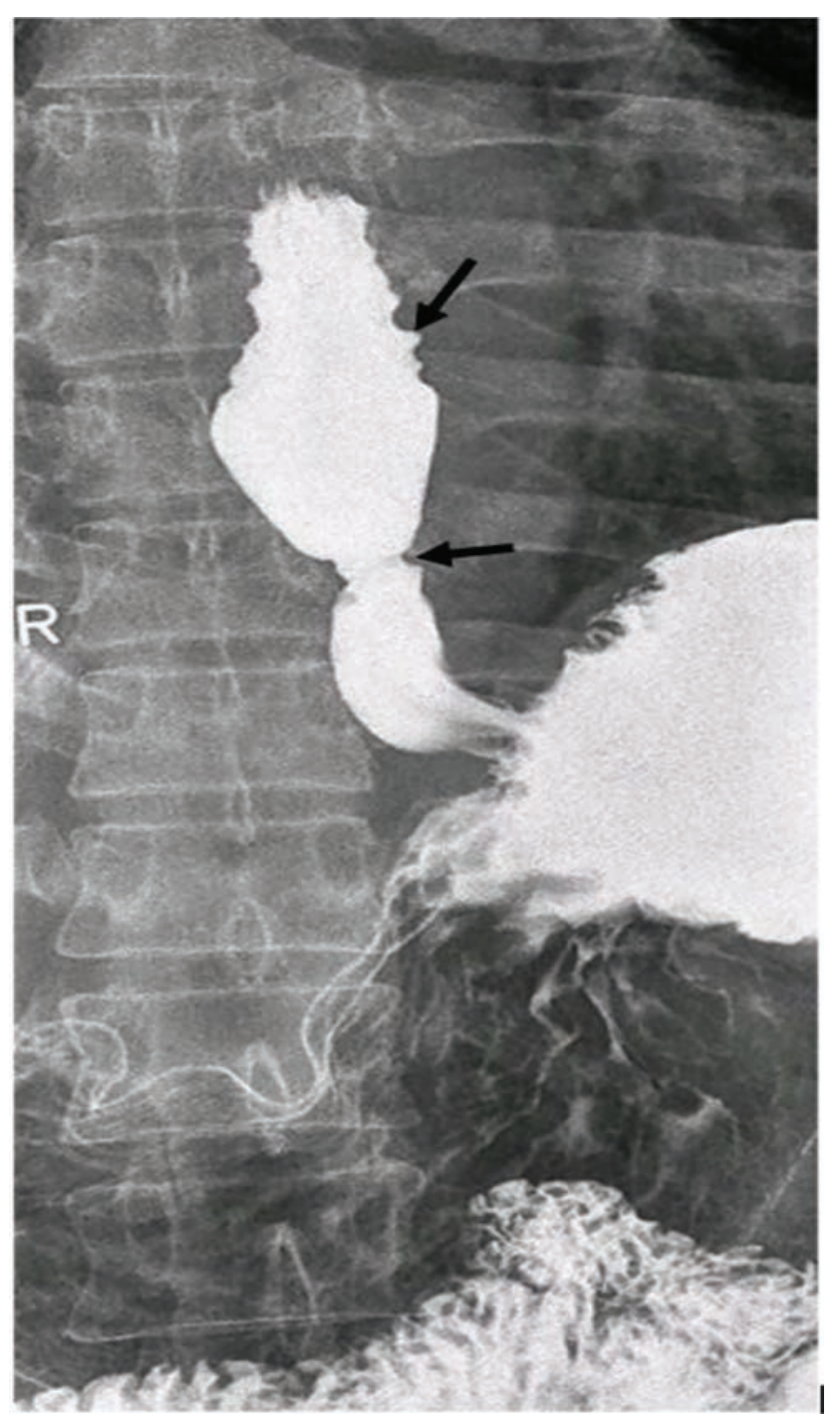

Fig. 6 Single-contrast barium study demonstrates serpginous indentations by the esophageal varices. 
thickening might not be distinguishable from esophagitis. Advanced esophageal varices are seen as worm-like filling defects and may extend up the mid- and upper thoracic esophagus (-Fig. 6). Varicoid esophageal carcinoma may mimic large esophageal varices and can be differentiated as esophagus with varices is distensible and shows peristalsis. ${ }^{11}$

Barium esophagography identifies all large esophageal varices (F2, F3), whereas sensitivity is reduced with small esophageal varices (F1). Esophagography has positive predictive value, negative predictive value, and accuracy of $89 \%, 83 \%$, and $87 \%$, respectively, and can be considered as a useful noninvasive method for patients to undergo prophylactic treatment. ${ }^{12}$

CT is a potential tool for noninvasive risk stratification of esophageal varices. Patients whose esophageal varices measure more than $5 \mathrm{~mm}$ at CT are more likely to have variceal hemorrhage.

On CT varices are well-defined tortuous structures which enhance like the adjacent vessels. Coronary venous collateral vessels are the most common varices seen at imaging. They are seen between the medial wall of the upper stomach, left lobe of the liver, and lesser omentum. Coronary vein measuring more than 5 to $6 \mathrm{~mm}$ on Doppler or CT is suggestive of portal hypertension (-Fig. 7).

Esophageal varices are located within the lower esophageal wall and are formed by dilated subepithelial and submucosal veins. They are drained by the anterior branch of the left gastric vein, while the posterior branch of left gastric vein drains paraesophageal collateral vessels. On CT, esophageal varices are intraluminal protrusions which enhance and may be associated with wall thickening ( - Fig. 8). Due to their intramural location, these esophageal varices are detected less often compared with the varices at other locations (-Fig. 7). ${ }^{13}$

Nonesophagogastric varices are known as ectopic varices and are most often located in the duodenum or jejunum (-Fig. 9). Gastric varices can be located in the gastric cardia
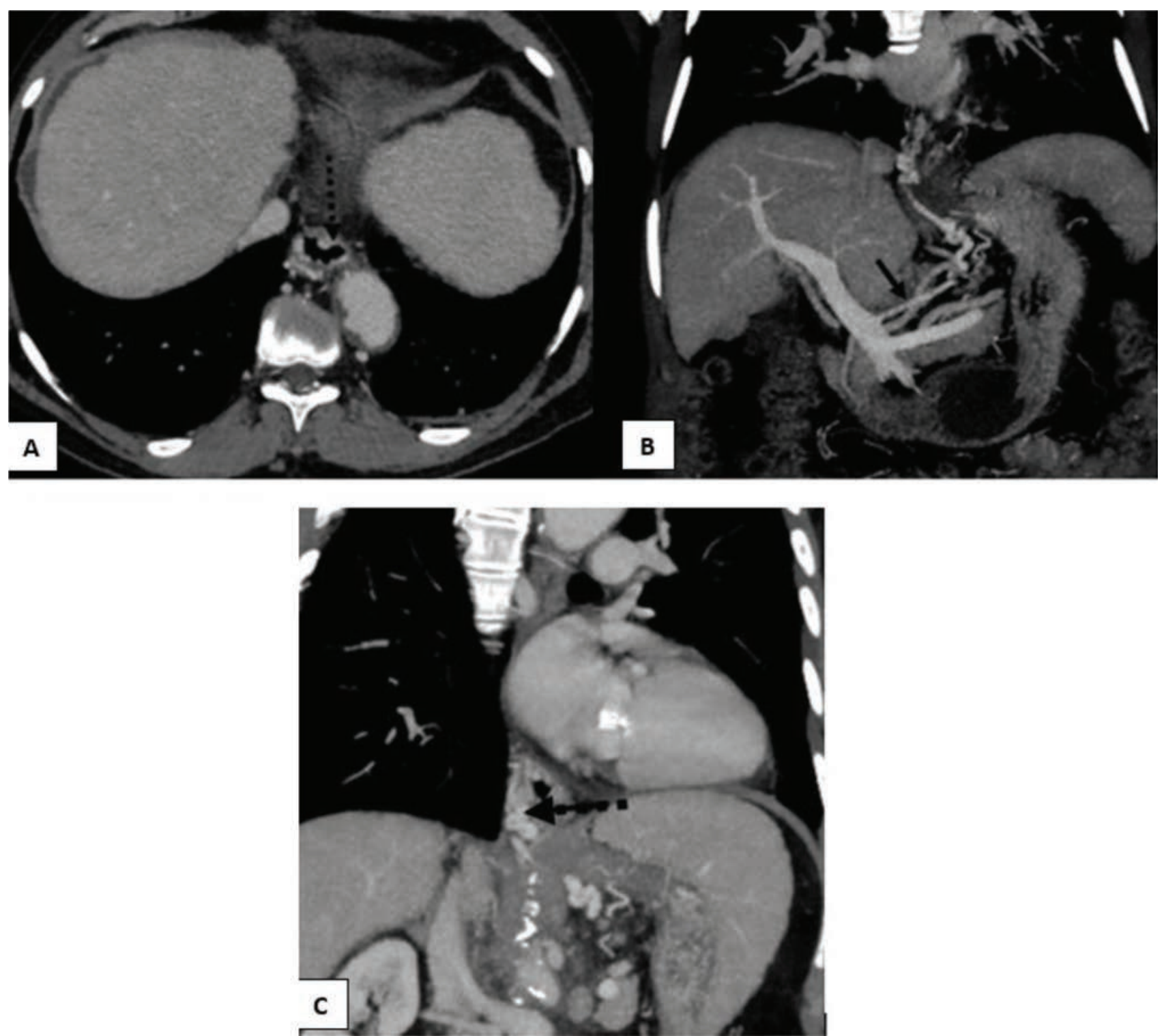

Fig. 7 (A-C) Contrast CT scan axial, coronal, and oblique coronal reformatted images demonstrate enhancing submucosal esophageal varices (dotted arrows) and prominent coronary vein (arrow). 


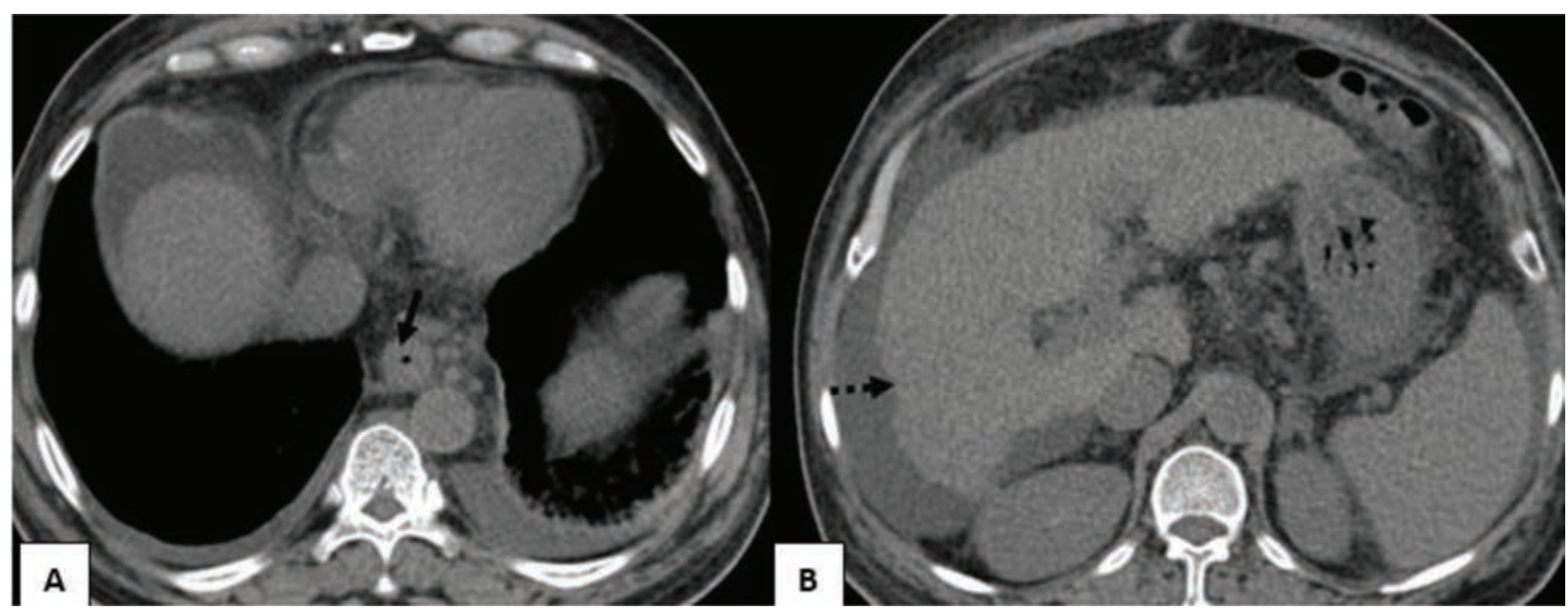

Fig. 8 (A, B) Noncontrast computed tomography demonstrates cirrhotic liver with nodular surface (dotted arrow) and circumferential esophageal wall thickening which was proven to be esophageal varices at endoscopy.
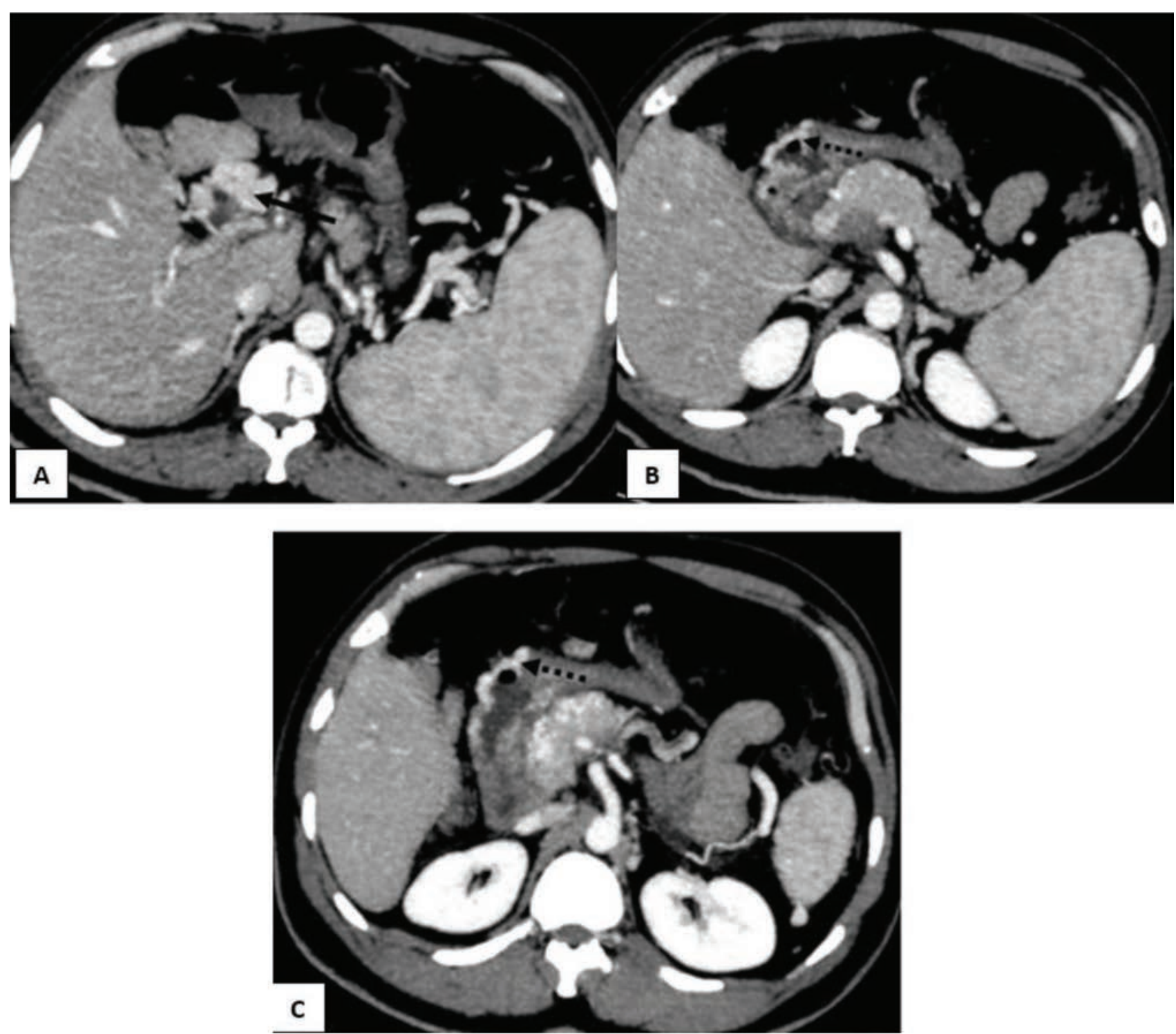

Fig. 9 (A-C) Axial-contrast computed tomography in a patient with extrahepatic portal venous obstruction demonstrates portal cavernoma (solid arrow) and ectopic duodenal varices (dotted arrows). 
or fundus and this is consistent with the boundary line of portosystemic shunting.

Gastric varices ( - Fig. 10) drain via two major pathways, to the azygous vein-superior vena cava through esophagealparaoesophageal varices (GOV1) and through the inferior phrenic vein into the left renal vein or the inferior vena cava (IGV1) or both pathways GOV2) ( - Fig. 2). The gastric variceal drainage into the left renal vein can be directly into the left vein or through the left adrenal vein $\left(\boldsymbol{\sim}\right.$ Fig. 11). ${ }^{14}$

Gastric varices after their formation in the submucosal aspect (intragastric/true varices) and communicate with extragastric/false varices through a fistula. The cranial extragastric varices are convoluted and intraperitoneal in the lesser sac and as they course down they become retroperitoneal and assume a vertical course (-Figs. 11-13). ${ }^{15}$

The afferent supply to the gastric varices is from the splenic vein and in essence this is a splenogastric-renal shunt (-Fig. 14).
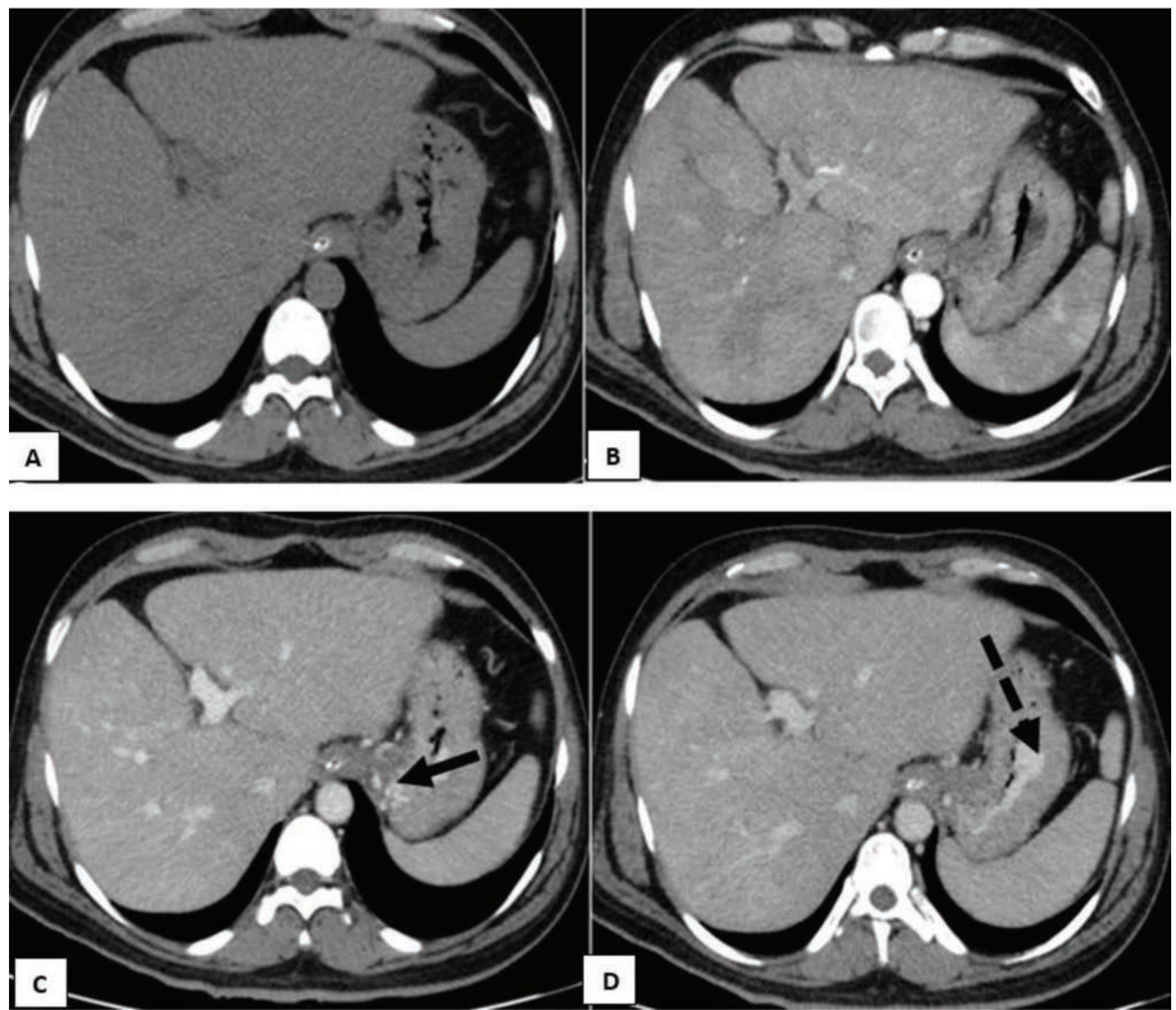

Fig. 10 (A-D) Cirrhotic patient presenting with massive hematemesis. Axial noncontrast, late arterial, portal, and venous phase computed tomography scans demonstrate gastric fundal varices (arrow) with active contrast extravasation (dotted arrows).
Direct splenic renal shunts occur without intervening gastric component or gastric varices. The splenorenal shunts can also directly drain into the inferior vena cava. The presentation of these splenorenal shunts is with hepatic encephalopathy rather than GI bleed. These are treated with embolization using plugs (-Figs. 14-17). . $^{16,17}$

\section{Portal Hypertensive Gastropathy (PHG), Portal Hypertensive Enteropathy (PHE), and Portal Hypertensive Colopathy (PHC) ${ }^{18}$}

Changes other than varices are frequently observed in the GI tract mostly in the stomach and, less commonly, in the small bowel and colon that occur due to vascular congestion in the GI mucosa. These are noninflammatory changes and are clinically important as they present as acute or chronic GI hemorrhage. Histologically dilatation and edema of the capillary blood vessels in the mucosal layer and veins in the submucosal layer are characteristic. In the stomach the appearances at endoscopy can be varied appearing as superficial reddening, 


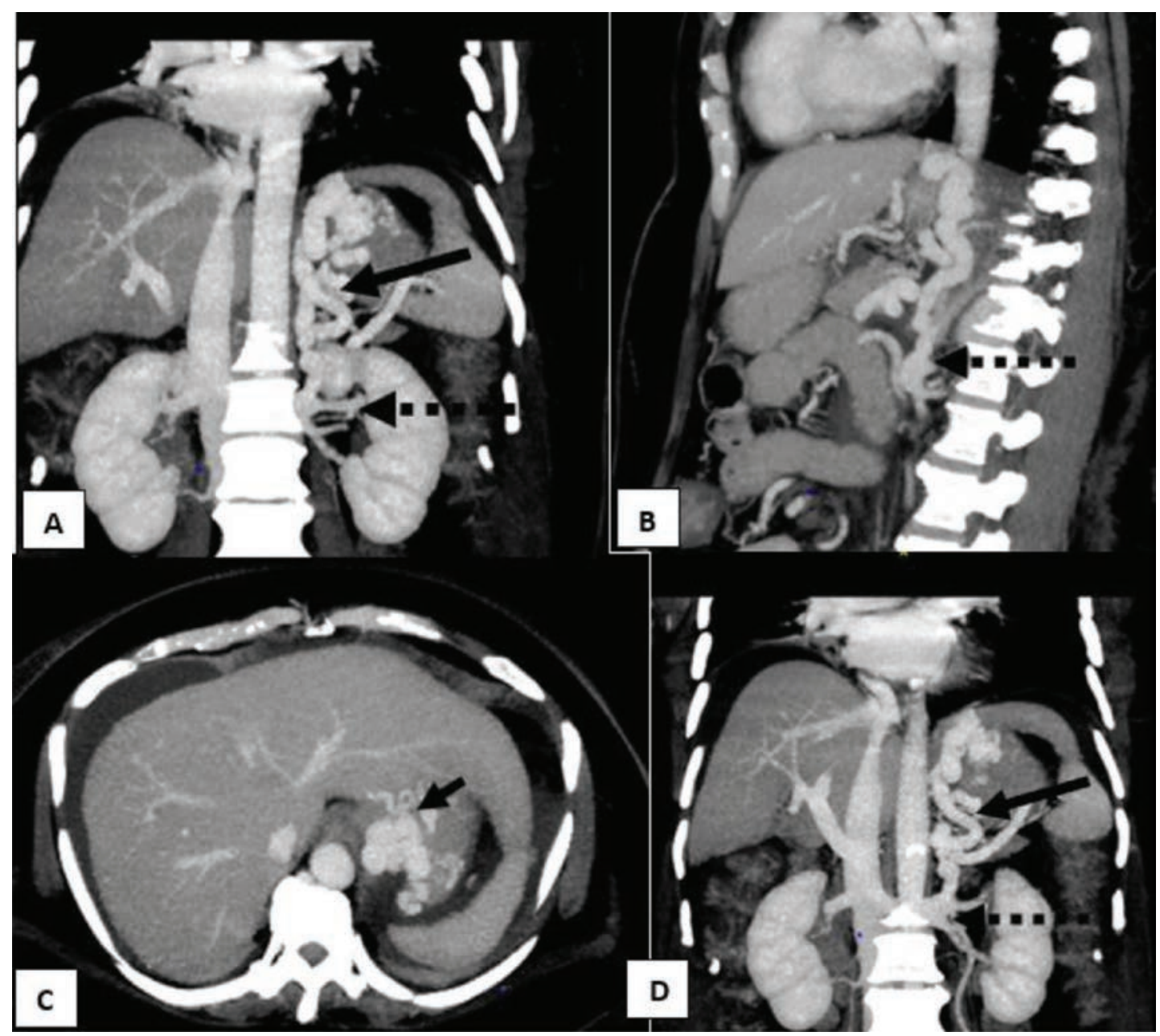

Fig. 11 (A-D) Axial, coronal, and sagittal maximum-intensity projection images in a patient with cirrhosis showing gastric varices in the fundus (short arrow), gastrorenal shunt (long arrow) draining into the left renal vein (dotted arrow). Note the convoluted cranial portion of the gastric varices and vertical course of the gastrorenal shunt caudally.

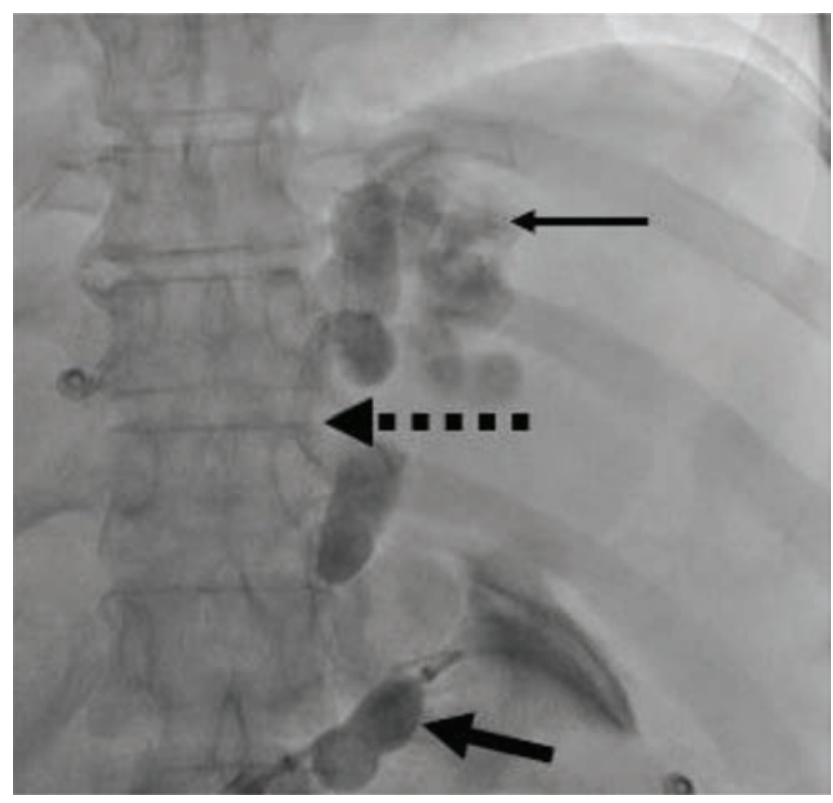

Fig. 12 Venogram from BRTO procedure (same patient as in Fig. 6) demonstrates balloon (thick arrow) inflated in the caudal gastrorenal shunt with filling of the vertical segment (dotted arrow) of the shunt and tortuous extragastric (false) and intragastric (true) varices (thin arrow). mosaic/snakeskin pattern of the gastric mucosa to cherry red spots and diffuse hemorrhage (-Fig. 18). ${ }^{19}$ In the small bowel $^{20}$ and large bowel ${ }^{21}$ they manifest as vascular lesions like angiodysplasia-like lesions; solitary/diffuse cherry red spots; or colitis-like abnormalities like edema, erythema, granularity, friability, and spontaneous bleeding.

Gastric antral vascular ectasia (GAVE) ${ }^{18}$ is a distinct entity that can occur in the presence of portal hypertension and also can be seen in the absence of portal hypertension as an incidental finding during routine endoscopy in some chronic ailments such as congestive heart failure, diabetes, renal failure, and connective tissue disorders. They appear as flat or slightly elevated red spots that can coalesce, forming red stripes that converge toward the pylorus creating a typical watermelon appearance and hence also called "watermelon stomach." Histologically they appear as mucosal capillary ectasia, with fibrin thrombi, spindle cell proliferation, and fibrohyalinosis of the ectatic capillaries.

\section{Portal Hypertensive Gastropathy Imaging}

PHG is predominantly an endoscopic diagnosis and few radiologic features have been described. 

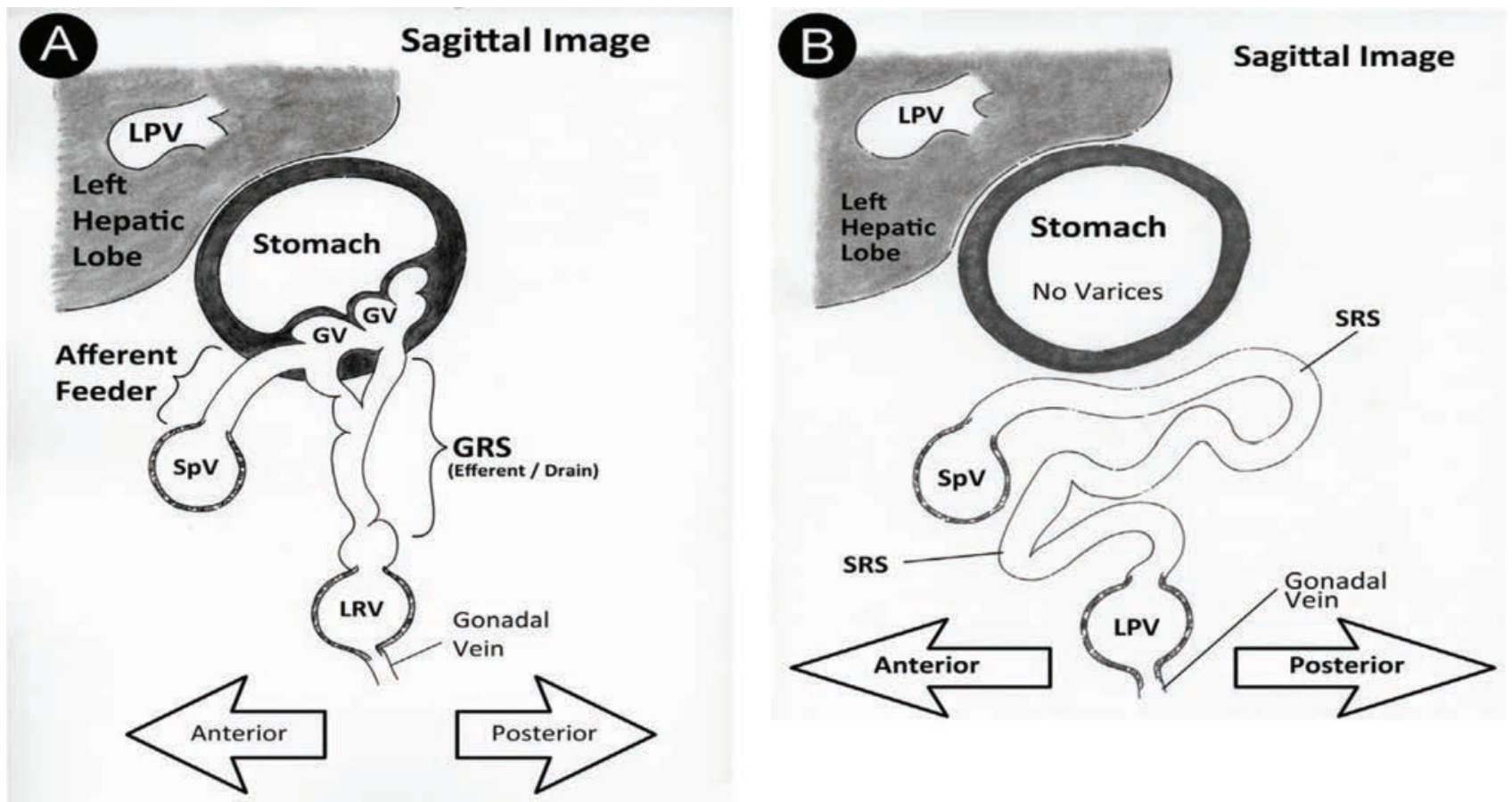

Fig. 13 (A, B) Sagittal illustrations depicting gastrorenal shunt and splenorenal shunt. (A) Gastrorenal shunt: The afferent portal venous feeders comes off the splenic vein (SpV) or portosplenic venous axis. This supplies the gastric varices (GV) that are in turn drained by the gastrorenal shunt (GRS) that empties into the left renal vein (LRV). (B) Splenorenal shunt (SRS): The afferent portal venous feeders come off the splenic vein $(\mathrm{SpV})$ or portosplenic venous axis. The SRS does not supply any varices and does not run through the wall of the gastrointestinal tract (GIT). The most common efferent drainage is the left renal vein (LRV). The SRS is commonly long and tortuous. Image courtesy: Saad et al. ${ }^{15}$

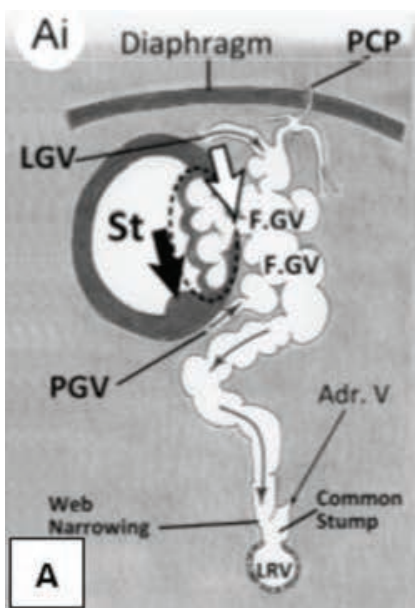

Sagittal Image
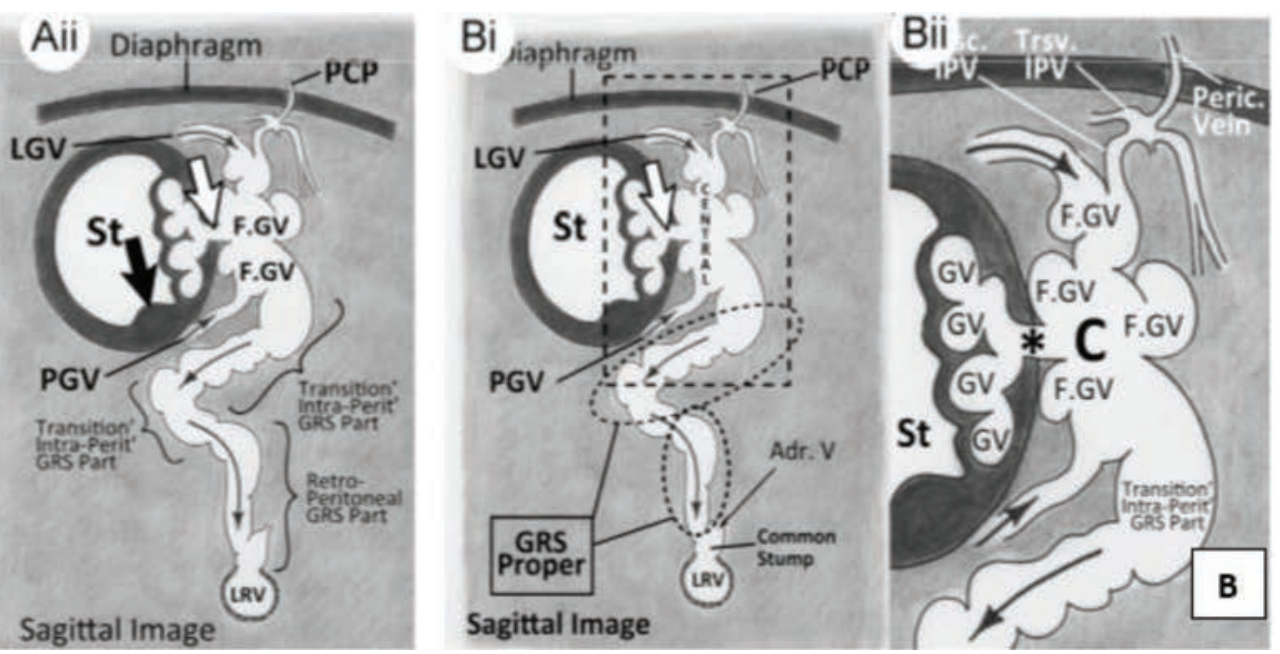

Fig. 14 (A, B) Sagittal illustrations depicting detailed anatomy of the gastric variceal system (GVS). The gastric variceal system is composed of the afferent portal venous feeders, the central variceal part, and the gastrorenal shunt. The central variceal part has the extragastric or false gastric varices (F.GV), the intragastric submucosal or true gastric varices (T.GV), and a perforator vein or varix communicating between the false and true GVs. Image courtesy: Saad et al. ${ }^{15}$

Transient gastric perfusion defect sign, which is a transient, segmental or subsegmental hypoattenuating mucosa in the fundus or body of the stomach on arterial phase imaging, showing normal attenuation on delayed-phase images (-Figs. 18 and $\mathbf{1 9}$ ) has sensitivity and specificity of $75 \%$ and $88.6 \%$, respectively. ${ }^{22}$
Contrast enhancement of the gastric inner layer in the delayed phase could represent gastric mucosal congestion and when seen in patients with portal hypertension suggests $\mathrm{PHG}^{23}$

PHG needs to be differentiated from GAVE syndrome. Distinction between them is extremely important as 


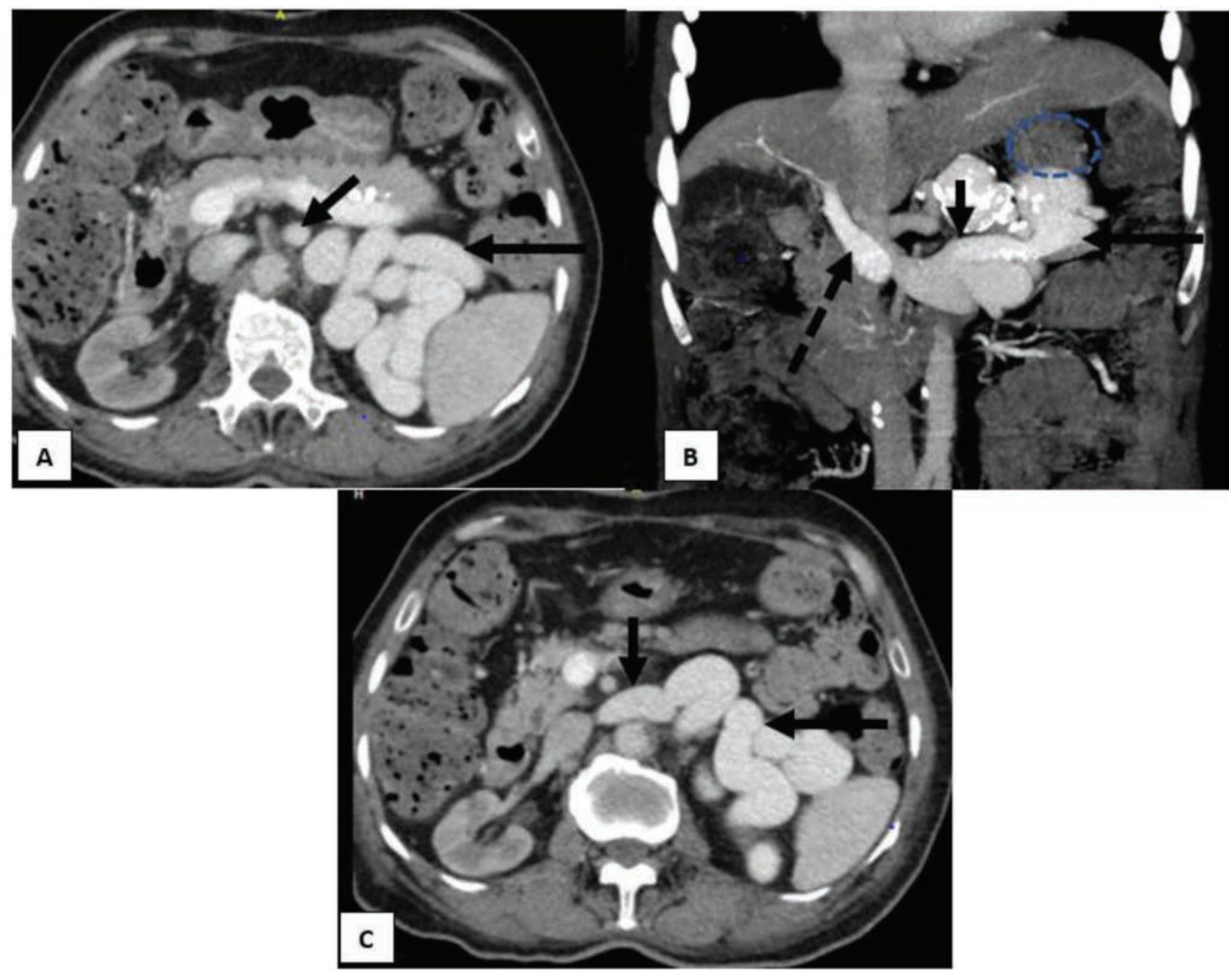

Fig. 15 (A-C) Axial multiplanar reformat and coronal maximum intensity projection images demonstrate large meandering splenorenal shunt (long arrow). Note the dilated left renal vein (short arrow) with the shunt opening almost parallel into it. Note the absence of gastric fundal varices (dotted circle).

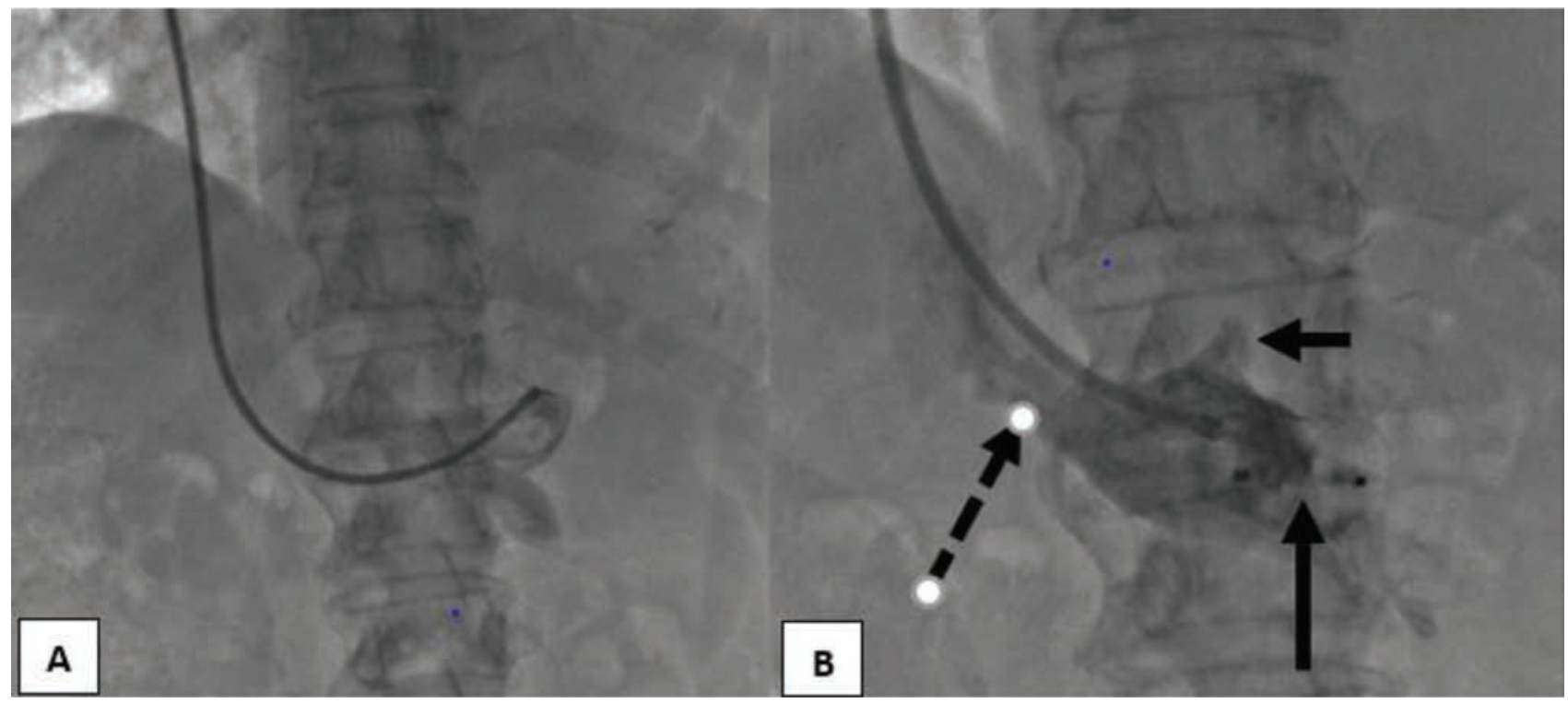

Fig. 16 (A, B) Venogram obtained during transjugular plug occlusion of the splenorenal shunt showing left adrenal vein (short arrow) and plug (long arrow) in the caudal part of the splenorenal shunt which opens parallel into the left renal vein (dotted arrow) (same patient as in $\boldsymbol{\sim}$ Fig. 10). 


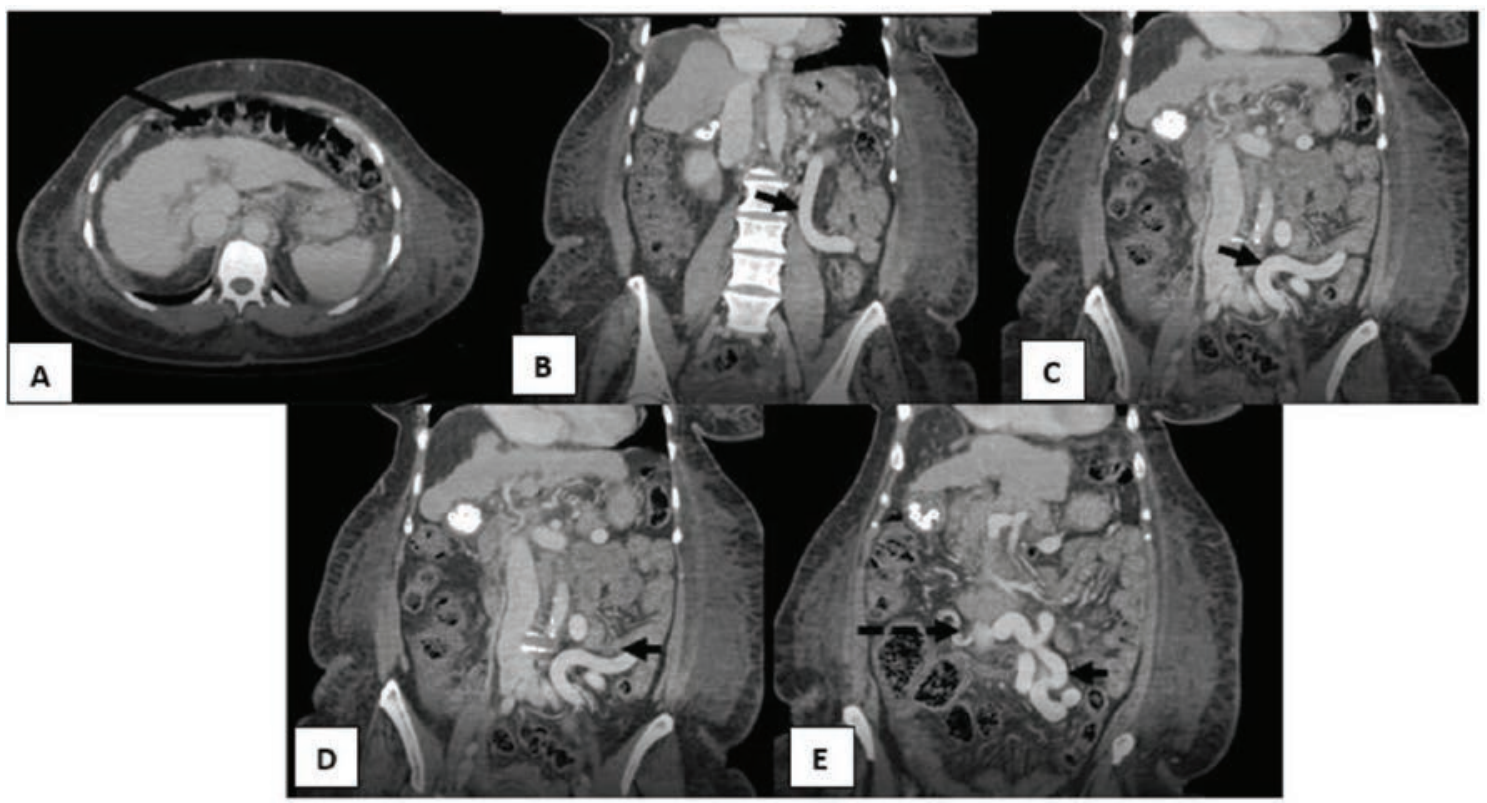

Fig. 17 (A-E) Axial and coronal images in a patient with cirrhosis and portal hypertension demonstrate shrunken liver with surface nodularity (long arrow) and large, tortuous shunt (short arrows) between the splenic vein and the inferior venacava (dotted arrow). Note the absence of gastric fundal varices (dotted circle). Also note cholelithiasis.

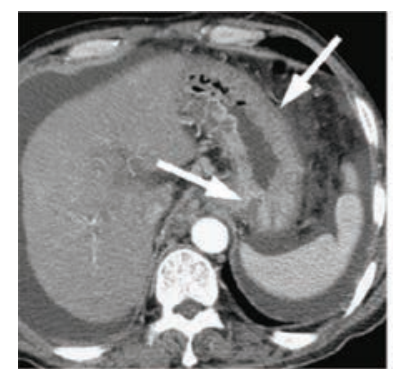

(A)

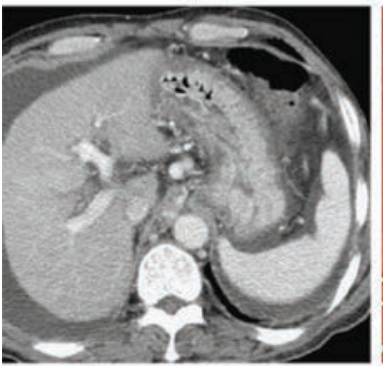

(C)

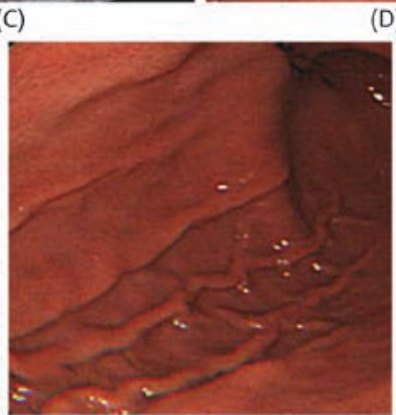

(E)

Fig. 18 Mild portal hypertensive gastropathy (PHG) in a 47-year-old man. Contrast enhanced computed tomography shows multifocal hypoattenuating mucosa (arrows) in the fundus and body of the greater curvature on (A) arterial phase, which returns to normal attenuation on (B) portal and (C) delayed phase images. Gastric endoscopy (D, E) shows a mosaic or snakeskin-like appearance in the fundus and body. Image courtesy: Kim et al. ${ }^{22}$

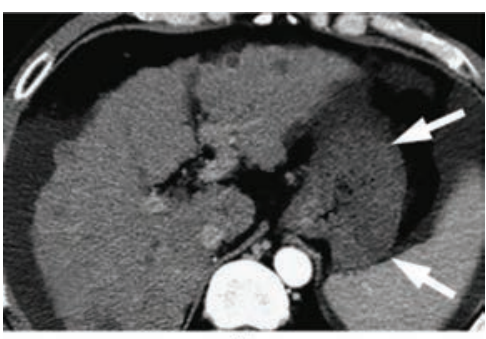

(A)
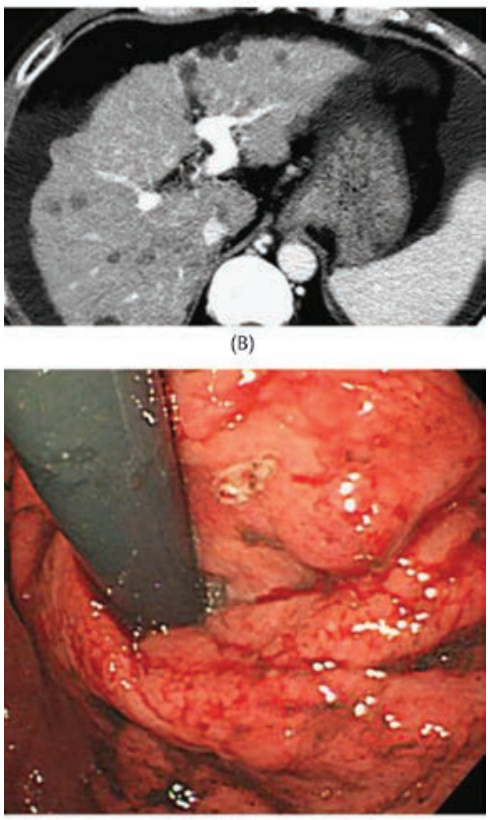

(C)

Fig. 19 Mild portal hypertensive gastropathy (PHG) in a 47-year-old man. Contrast enhanced computed tomography shows multifocal hypoattenuating mucosa (arrows) in the fundus and body of the greater curvature on (A) arterial phase, which returns to normal attenuation on (B) portal and (c) delayed phase images. Gastric endoscopy (D, E) shows a mosaic or snakeskin-like appearance in the fundus and body. Image courtesy: Kim et al. ${ }^{22}$ 
treatment differs. PHG responds to a reduction in portal pressures while GAVE syndrome does not. GAVE syndrome typically occurs in noncirrhotic patients and is limited to the antrum and pylorus, whereas classic PHG exclusively involves the fundus and body.

\section{Left-Sided Portal Hypertension}

Left-sided portal hypertension accounts for $\sim 5 \%$ of portal hypertension cases. Portal hypertension generally develops due to thrombosis of portal vein but can also develop due to compression over the vein. Most common causes of splenic vein thrombosis leading to left-sided portal hypertension include pancreatitis (-Fig. 20), pancreatic and nonpancreatic tumor (-Fig. 21) either directly invading the vein or compressing it, and postdistal pancreatectomy. Lymphoproliferative disease can also cause nonthrombotic left-sided portal hypertension. ${ }^{24}$

As a result of splenic vein obstruction, the short gastric veins route the splenic venous flow to the stomach leading to formation of collaterals in the gastric fundus.

There are no guidelines for management of patients without GI bleed. Patients presenting with GI bleed are treated with endoscopic glue injection. Splenectomy is the definitive surgical treatment for left-sided portal hypertension. ${ }^{25-27}$ Splenic artery embolization for the treatment of left-sided portal hypertension has been used with success, especially in patients who are poor surgical candidates, or as a bridge to surgery. ${ }^{27,28}$

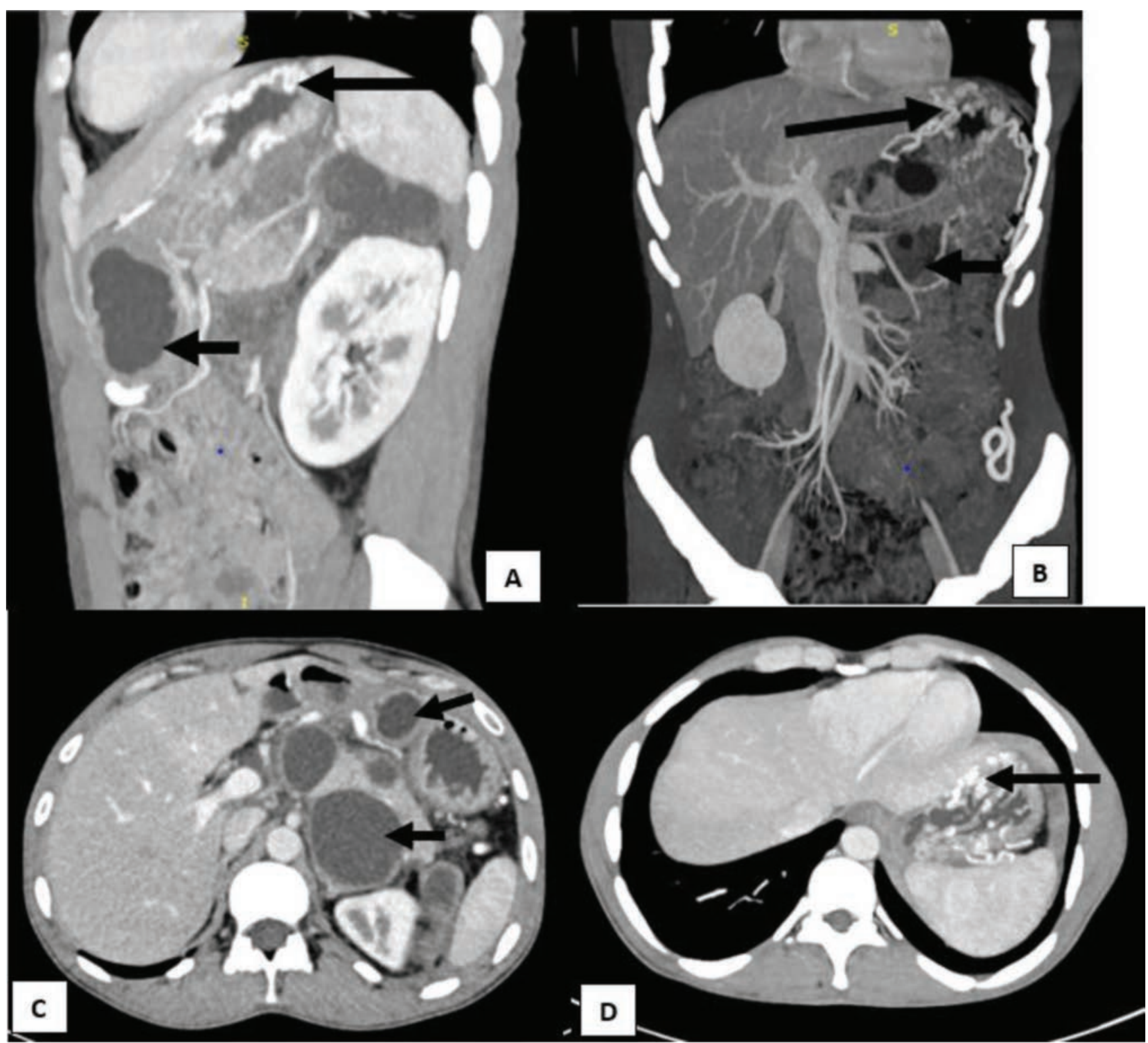

Fig. 20 (A-D) Axial MPR and axial, sagittal, and coronal MIP images demonstrate multiple intra- and peripancreatic fluid collections (short arrows) with nonvisualization of the splenic vein and fundal gastric varices (arrows). 


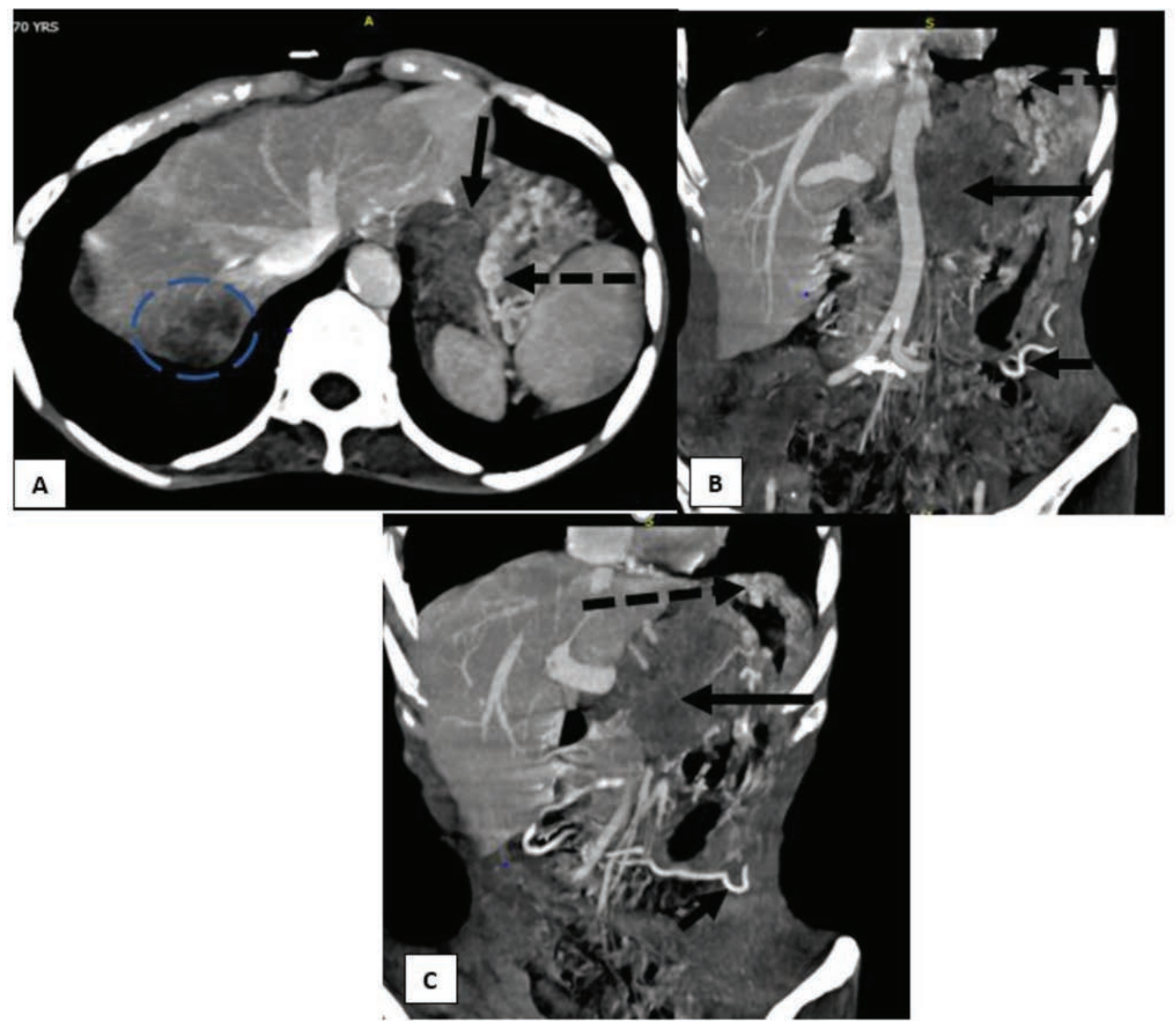

Fig. 21 (A-C) Axial and coronal maximum intensity projection images from venous phase CT demonstrates a large pancreatic mass (arrow) encasing the splenic vein (not seen here) with resultant gastric fundal varices (dotted arrow) and omental collaterals (short arrow). Also seen is a right lobe liver metastasis (dotted circle).

\section{Treatment of Varices}

Many years ago, surgery was the only treatment available for esophagogastric varices. Emergency operations were performed for the treatment of bleeding from esophagogastric varices, but many patients died of liver failure. In 1968, the Japan Society for the Study of Surgery for Portal Hypertension held its first meeting which opened avenues of different treatment modalities for the varices. Thus, in 1970s, techniques for interventional radiology (IR) were developed and adopted, which improved the survival rates of patients with bleeding esophagogastric varices. In the 1980s, endoscopic treatment further improved survival rates. Over the last four decades there has been refinement in the way portal hypertension is managed endoscopically.

1. Screening and surveillance.

2. Primary prophylaxis.

a. Pharmacologic treatment.

b. Endoscopic management.
- Esophageal varices.

- Gastric varices.

- Ectopic varices.

- PHG and GAVE.

3. Acute variceal bleeding.

4. Secondary prophylaxis.

\section{Screening and Surveillance}

Risk of variceal development is low in patients with a platelet count $>1,50,000$ and liver stiffness less than $20 \mathrm{kPa}$ on transient elastography. Endoscopy should be performed for those with thrombocytopenia and or liver stiffness measurement $>20 \mathrm{kPa}$. The frequency of screening should be once in 2 to 3 years in those with compensated cirrhosis and no varices at index endoscopy or annually in those with small varices or in decompensated cirrhosis. Predictors of bleeding from varices include decompensated disease, advanced Child-Pugh score, size of the varices, and presence of high-risk stigmata noted at endoscopy (red wale marks/cherry red spots). 


\section{Primary Prophylaxis}

This refers to treatment of the varices prior to the onset of bleeding. Guidelines recommend pharmacologic prophylaxis with nonselective $\beta$-blockers or endoscopic treatment. The nonselective $\beta$-blockers used are nadolol, propranolol, and carvedilol. The dose of the drugs are titrated to maximum tolerated dose needed to achieve a resting heart rate of 55 to 60 beats per minute, a drop in HVPG of at least $10 \%$ from baseline, or $<12 \mathrm{~mm} \mathrm{Hg}$ with chronic treatment.

Endoscopic treatment is recommended for medium- to large-size varices, intolerance to nonselective $\beta$-blockers, or the presence of high-risk stigmata.

Esophageal varices are treated by endoscopic band ligation rather than sclerotherapy as the latter is associated with higher risk of complications. In general patients need three to four sessions for eradication of the varices (-Fig. 22). Gastric varices are treated with injection of cyanoacrylate glue into the varices ( - Fig. 23). The Baveno consensus does not recommend primary glue injection to the gastric varices but should continue medical prophylaxis and explore interventional radiological procedures. However, prophylactic glue injection as a primary prophylaxis is used in patients undergoing prophylactic esophageal variceal band ligation $(E V L)$ and in those who have bled from esophageal varices. This is because of a theoretically obliteration of the esophageal varices that increases the risk of bleeding from gastric varices. The use of cyanoacrylate glue injection to duodenal and rectal varices for the treatment of ectopic varices has shown good results. transjugular intrahepatic portosystemic shunt is recommended for prevention of rebleeding.

PHG is a distinct entity and an important cause of GI bleeding. During acute bleeding the gastropathy is managed with vasoactive drugs like octreotide, terlipressin, and endoscopic methods like argon plasma coagulation (APC) and hemospray. Guidelines recommend nonselective $\beta$-blockers. Refractory cases require TIPS or surgical shunts as a salvage therapy.
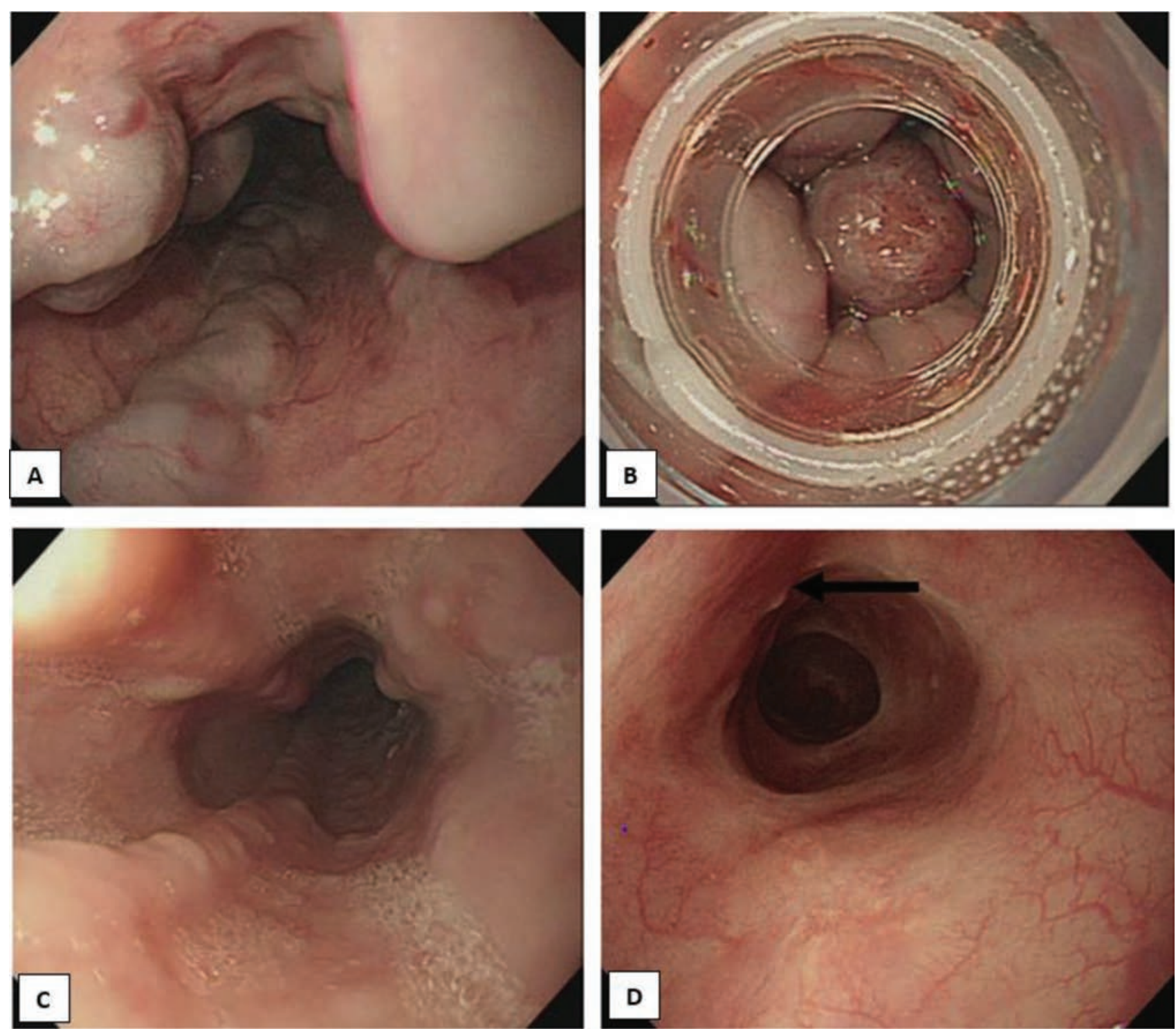

Fig. 22 (A) Endoscopic findings before treatment. (B) Just after treatment session. (C) Just before the third treatment session. (D) One year after the eradication which shows post esophageal variceal band ligation (EVL) scar marks (arrow). 

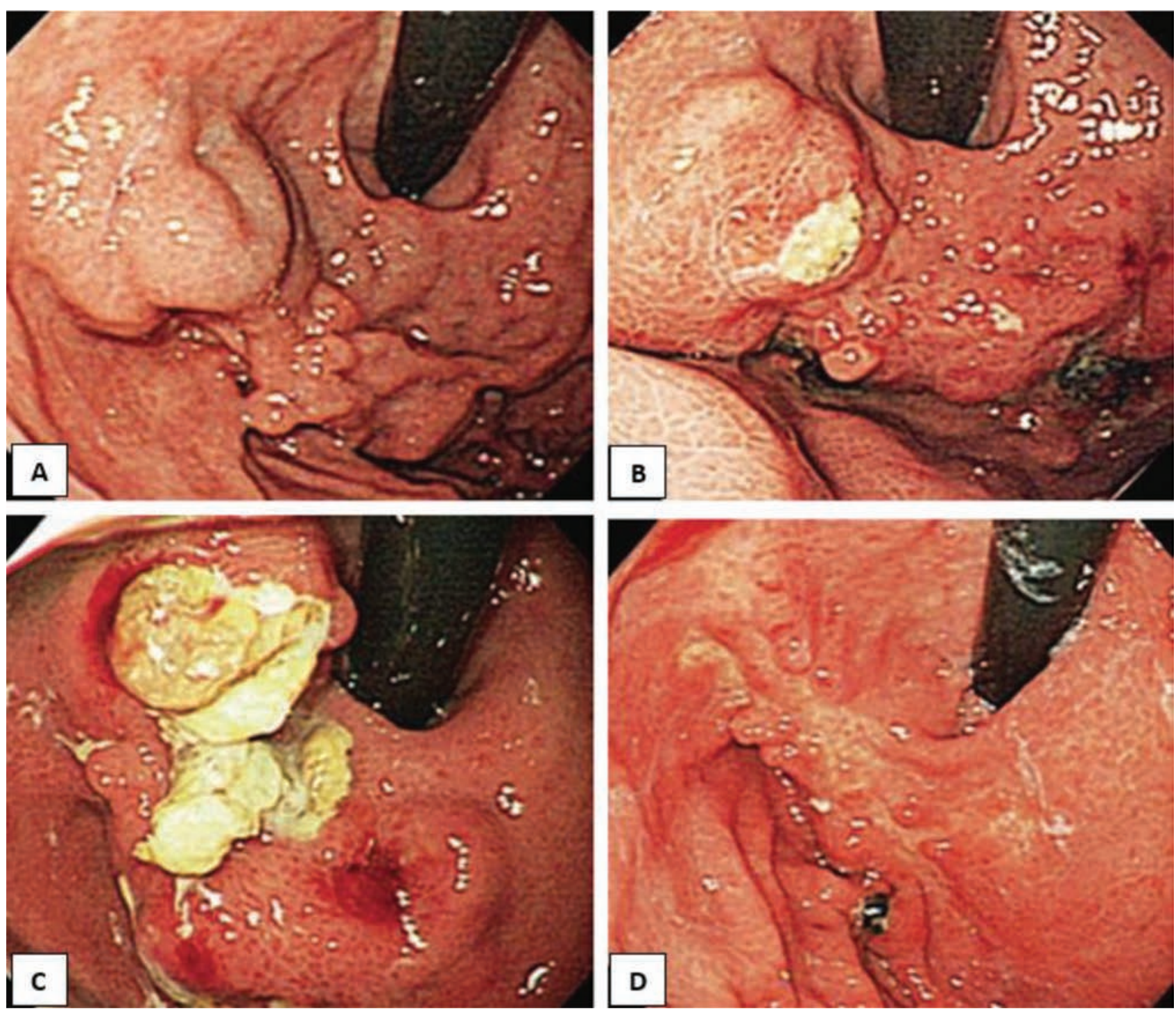

Fig. 23 (A) Endoscopic findings before treatment. (B) One week after injection of glue. (C) Three weeks after injection of glue. (D) One year after injection of glue.

GAVE is another distinct entity that can be observed in cirrhotics and is an important cause of bleeding. APC is effective and may require multiple sessions spaced 3 to 6 weeks apart. Recurrence is a norm after APC as the deeper submucosal vessels may not be obliterated by APC and hence EVL of the lesions has shown to be more effective in the treatment of GAVE.

\section{Acute Variceal Bleeding}

Acute esophageal variceal bleeding is tackled by either endoscopic sclerotherapy (ES) by injecting a sclerosant agent like ethanolamine oleate intra/paravariceal or either by EVL. Comparison between ES and EVL has shown that EVL is superior than ES. Newer modalities like hemospray (a nano powder) licensed for use in nonvariceal upper GI bleeding have proven to be safe and effective in preliminary studies for use as a bridge to more definitive therapy. In treatment failure balloon tamponade using a Sengstaken-Blakemore tube, a Minnesota tube, or even a specially designed esophageal stent (Danis Ella-SX stent, ELLA-CS, s.r.o., Hradec Kralove,
Czech Republic) that causes a tamponade effect in the esophagus have been used as a bridge to more definitive therapy.

\section{Secondary Prophylaxis}

This refers to treating varices after an index bleeding has occurred with a view to obliterate varices and prevent rebleeding episodes. Consensus guidelines recommend follow-up endoscopy in 3 to 4 weeks after index bleeding and thereafter at 1- to 3-month intervals till the varices are eradicated. The average eradication time in $\sim 3$ to 4 sessions.

\section{Interventional Management of Gastric Varices}

TIPS procedure involves creating an artificial channel between the hepatic vein and the portal venous system with a stent graft, with the aim to reduce the portal pressure and in turn reduce the variceal bleed. TIPS could be performed alone or combined with obliteration/embolization of refractory or recurrent esophageal varices (-Fig. 24), acute 


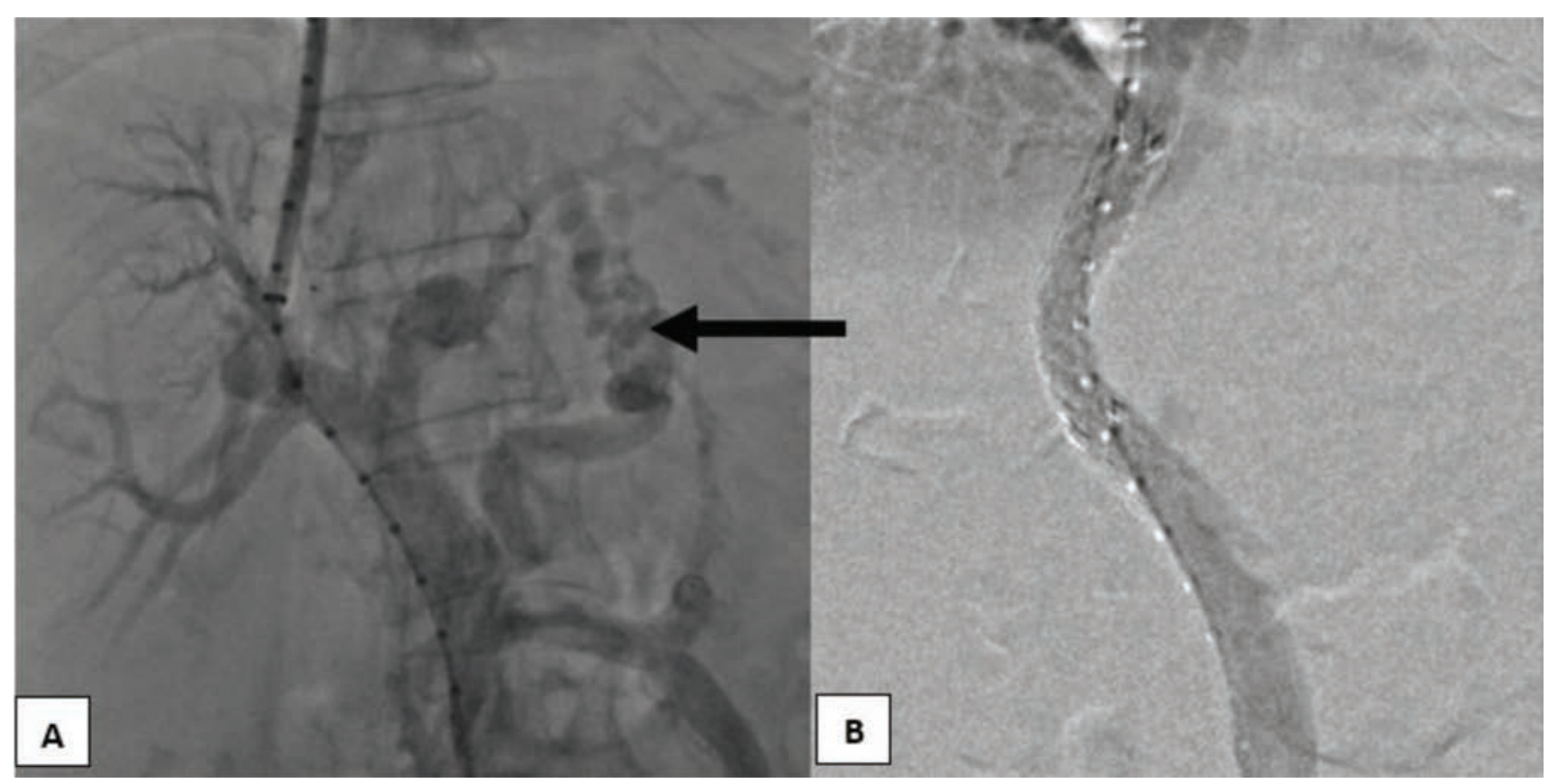

Fig. 24 (A, B) Venogram obtained during a TIPS procedure from a pigtail catheter in the superior mesenteric vein showing esophagogastric collaterals (arrow) which were not visualized after creation of a TIPS.

esophageal variceal bleeding, and refractory bleeding gastric varices. ${ }^{29,30}$ Complications of TIPS include hepatic encephalopathy due to shunting portal blood. ${ }^{31,32}$

Balloon-occluded retrograde transvenous obliteration (BRTO) involves accessing the left renal vein and the gastrorenal shunt, inflating a balloon in the gastrorenal shunt, progressing tip of a microcatheter through the shunt as close to gastric varices as possible, and obliterating the gastric varices by instilling a combination of sclerosant foam (sodium tetradecyl sulfate, air, lipiodol) ( - Fig. 12). ${ }^{33-35}$ Modifications to the BRTO procedure with the use of vascular plugs/coils (plug assisted retrograde transvenous obliteration/coil Assisted retrograde transvenous obliteration) are also practiced and are effective. ${ }^{36}$

Gastric varices that drain through the esophageal-paraesophageal venous system have significant portal hypertension and are like esophageal varices in their behavior; they respond well to endoscopic therapy or TIPS. Gastric varices that drain via the gastrorenal shunt do not have high pressures as seen with gastroesophageal varices but have high flow volumes and velocity and, hence, are less likely to respond to pressure-reducing procedures like TIPS. ${ }^{15}$

Advantages of BRTO over TIPS are that it is less invasive; patients with poor hepatic reserve and encephalopathy can undergo BRTO. BRTO may improve the hepatic function. The downside to BRTO is that it increases the portal flow and exacerbates esophageal varices. ${ }^{37,38}$

CT depicts the anatomy of these varices and the presence or absence of shunts with detail, ${ }^{39}$ and is also helpful in follow-up to look for resolution of these varices. ${ }^{40}$

\section{Conclusion}

Portal hypertension can result from multiple cirrhotic and noncirrhotic causes. PHG and gastroesophageal varices are important complications arising from portal hypertension. Endoscopy is the first-line modality to diagnose PHG and varices. Imaging plays an important role in assessing the presence of varices, delineating the anatomy, and selecting patients for suitable treatment. Medical, endoscopic, and interventional modalities are used to treat these conditions.

\section{Conflict of Interest}

None declared.

\section{References}

1 Widrich WC, Srinivasan M, Semine MC, Robbins AH. Collateral pathways of the left gastric vein in portal hypertension. AJR Am J Roentgenol 1984;142(2):375-382

2 Sharma M, Rameshbabu CS. Collateral pathways in portal hypertension. J ClinExpHepatol 2012;2(4):338-352

3 da Silva A, Navarro T, Oliveira S, Faion A, Ferreira L. Posterior gastric vein, portal hypertension. Rev Col Bras Cir 1999;XXVI(5)

4 Johns TN, Evans BB. Collateral pathways in portal hypertension. Ann Surg 1962;155:838-845

5 Moubarak E, Bouvier A, Boursier J, et al. Portosystemic collateral vessels in liver cirrhosis: a three-dimensional MDCT pictorial review. Abdom Imaging 2012;37(5):746-766

6 Sharma M, Babu CS, Dhiman RK, Chawla Y. Induced hypotension in the management of acute hemobilia during therapeutic ERCP in a patient with portal biliopathy (with videos) Gastrointest Endosc 2010;72(6):1317-1319

7 D’Amico G, De Franchis R. Cooperative Study Group. Upper digestive bleeding in cirrhosis. Post-therapeutic outcome and prognostic indicators. Hepatology 2003;38(3):599-612

8 de Franchis R. Baveno VI Faculty. Expanding consensus in portal hypertension: report of the Baveno VI Consensus Workshop: stratifying risk and individualizing care for portal hypertension. J Hepatol 2015;63(3):743-752

9 Sarin SK, Lahoti D, Saxena SP, Murthy NS, Makwana UK. Prevalence, classification and natural history of gastric varices: 
a long-term follow-up study in 568 portal hypertension patients. Hepatology 1992;16(6):1343-1349

10 Watanabe N, Toyonaga A, Kojima S, et al. Current status of ectopic varices in Japan: results of a survey by the Japan Society for Portal Hypertension. Hepatol Res 2010;40(8):763-776

11 Eisenberg R, Gastrointestinal Radiology. Philadelphia, PA: Lippincott Williams and Wilkins;2003:125-130

12 Farber E, Fischer D, Eliakim R, et al. Esophageal varices: evaluation with esophagography with barium versus endoscopic gastroduodenoscopy in patients with compensated cirrhosisblinded prospective study. Radiology 2005;237(2):535-540

13 Cho KC, Patel YD, Wachsberg RH, Seeff J. Varices in portal hypertension: evaluation with CT. Radiographics 1995;15(3): 609-622

14 Kiyosue H, Ibukuro K, Maruno M, Tanoue S, Hongo N, Mori H. Multidetector CT anatomy of drainage routes of gastric varices: a pictorial review. Radiographics 2013;33(1):87-100

15 Saad WE. Vascular anatomy and the morphologic and hemodynamic classifications of gastric varices and spontaneous portosystemic shunts relevant to the BRTO procedure. Tech Vasc Interv Radiol 2013;16(2):60-100

16 Laleman W, Simon-Talero M, Maleux G, et al. EASL-CLIFConsortium. Embolization of large spontaneous portosystemic shunts for refractory hepatic encephalopathy: a multicenter survey on safety and efficacy. Hepatology 2013; 57(6):2448-2457

17 Uflacker R, Silva AdeO, d'Albuquerque LA, Piske RL, Mourão GS. Chronic portosystemic encephalopathy: embolization of portosystemic shunts. Radiology 1987;165(3):721-725

18 Payen JL, Calès P, Voigt JJ, et al. Severe portal hypertensive gastropathy and antral vascular ectasia are distinct entities in patients with cirrhosis. Gastroenterology 1995;108(1): 138-144

19 McCormack TT, Sims J, Eyre-Brook I, et al. Gastric lesions in portal hypertension: inflammatory gastritis or congestive gastropathy? Gut 1985;26(11):1226-1232

20 Kodama M, Uto H, Numata M, et al. Endoscopic characterization of the small bowel in patients with portal hypertension evaluated by double balloon endoscopy. J Gastroenterol 2008; 43(8):589-596

21 Bini EJ, Lascarides CE, Micale PL, Weinshel EH. Mucosal abnormalities of the colon in patients with portal hypertension: an endoscopic study. GastrointestEndosc 2000;52(4):511-516

22 Kim TU, Kim S, Woo SK, et al. Dynamic CT of portal hypertensive gastropathy: significance of transient gastric perfusion defect sign. Clin Radiol 2008;63(7):783-790

23 Ishihara K, Ishida R, Saito T, Teramoto K, Hosomura Y, Shibuya H. Computed tomography features of portal hypertensive gastropathy. J Comput Assist Tomogr 2004;28(6):832-835

24 Walker L, Kumari D, Bochnakova T, Davidson J, Patel I, Tavri S. Left sided portal hypertension in the presence or absence of splenic vein thrombosis: a single tertiary center experience): J Vasc Interv Radiol 2018;29(4)-231-233

25 Koklu S, Coban S, Yuksel O, Arhan M. Left-sided portal hypertension. Dig Dis Sci 2007;52(5):1141-1149
26 Pereira P, Peixoto A. Left-Sided Portal Hypertension: A Clinical Challenge. GE Port J Gastroenterol 2015;22(6):231-233

27 de Franchis R; Baveno V Faculty. Revising consensus in portal hypertension: report of the Baveno $\mathrm{V}$ consensus workshop on methodology of diagnosis and therapy in portal hypertension. J Hepatol 2010;53(4):762-768

28 Sebastian B, Singhal S, Madhurkar R, Alex A, UthappaM. Role of splenic artery embolization in gastric variceal hemorrhage due to sinistral portal hypertension. Journal of Clinical Interventional Radiology 2019;3:27-36

29 Patidar KR, Sydnor M, Sanyal AJ. Transjugular intrahepatic portosystemic shunt. Clin Liver Dis 2014;18(4):853-876

30 Keller FS, Farsad K, Rosch J. The transjugular intrahepatic portosystemic shunt: technique and instruments. Tech Vasc Interv Radiol 2016;19(1):2-9

31 Shah RP, Sze DY. Complications duringtransjugular intrahepatic portosystemic shunt creation. Tech Vasc Interv Radiol 2016;19(1):61-73

32 Suhocki PV, Lungren MP, Kapoor B, Kim CY. Transjugular intrahepatic portosystemic shunt complications: prevention and management. Semin Intervent Radiol 2015;32(2):123-132

33 Saad WE, Kitanosono T, Koizumi J, Hirota S. The conventional balloon-occluded retrograde transvenous obliteration procedure: indications, contraindications, and technical applications. Tech Vasc Interv Radiol 2013;16(2):101-151

34 ParkJK, Saab S, Kee ST, et al. Balloon-occluded retrograde transvenous obliteration (BRTO) for treatment of gastric varices: review and meta-analysis. Dig Dis Sci 2015;60(6):1543-1553

$35 \mathrm{Kim}$ YH, Kim YH, Kim CS, Kang UR, Kim SH, Kim JH. Comparison of balloon-occluded retrograde transvenous obliteration (BRTO) using ethanolamine oleate (EO), BRTO using sodium tetradecyl sulfate (STS) foam and vascular plug-assisted retrograde transvenous obliteration (PARTO) Cardiovasc Intervent Radiol 2016;39(6):840-846

36 Kim DJ, Darcy MD, Mani NB, et al. Modified balloon-occluded retrograde transvenous obliteration (BRTO) techniques for the treatment of gastric varices: vascular plug-assisted retrograde transvenous obliteration (PARTO)/coil-assisted retrograde transvenous obliteration (CARTO)/balloon-occluded antegradetransvenous obliteration (BATO) Cardiovasc Intervent Radiol 2018;41(6):835-847

37 Wang ZW, Liu JC, Zhao F, et al. Comparison of the effects of TIPS versus BRTO on bleeding gastric varices: a meta-analysis. Can J Gastroenterol Hepatol 2020;2020:5143013

38 Saad WE, Darcy MD. Transjugular intrahepatic portosystemic shunt (TIPS) versus balloon-occluded retrograde transvenous obliteration (BRTO) for the management of gastric varices. Semin Intervent Radiol 2011;28(3):339-349

39 Al-Osaimi AM, Sabri SS, Caldwell SH. Balloon-occluded retrograde transvenous obliteration (BRTO): preprocedural evaluation and imaging. SeminInterventRadiol 2011;28(3):288-295

40 Sauer BG, Sabri SS, Shami VM, Al-Osaimi AM. Balloon-occluded retrograde transvenous obliteration (BRTO): follow-up and postprocedural imaging. Semin Intervent Radiol 2011;28(3): 325-332 